\title{
Structural Folds: Generative Disruption in Overlapping Groups ${ }^{1}$
}

\author{
Balázs Vedres \\ Central European University \\ David Stark \\ Columbia University
}

\begin{abstract}
Entrepreneurial groups face a twinned challenge: recognizing and implementing new ideas. We argue that entrepreneurship is less about importing ideas than about generating new knowledge by recombining resources. In contrast to the brokerage-plus-closure perspective, we address the overlapping of cohesive group structures. In analyzing the network processes of intercohesion, we identify a distinctive network topology: the structural fold. Actors at the structural fold are multiple insiders, facilitating familiar access to diverse resources. Our data set records personnel ties among the largest 1,696 Hungarian enterprises from 1987 to 2001. First, we test whether structural folding contributes to group performance. Second, because entrepreneurship is a process of generative disruption, we test the contribution of structural folds to group instability. Third, we move from dynamic methods to historical network analysis and demonstrate that coherence is a property of interwoven lineages of cohesion, built up through repeated separation and reunification.
\end{abstract}

Business groups face two key challenges in their entrepreneurial mode of operation: to recognize sources of novel ideas and to secure the means to implement them. Recent thinking suggests that brokerage ties of connectivity outside the group provide contact with new ideas in the environment and that cohesive ties of closure within the group provide trust and mutual

\footnotetext{
${ }^{1}$ Research for this article was supported by a grant from the National Science Foundation, no. 0616802. We are alternating the order of authors' names across a series of papers produced from our broader project on historical network analysis. For their comments, criticisms, and suggestions, we are grateful to Peter Bearman, Laszlo Bruszt, Monique Girard, David Lazer, David I. Levine, Anna Mitschele, Guido Moellering, John Padgett, Roger Schoenman, Tamás Vicsek, and Douglas R. White. Our thanks to the Institute of Advanced Study, University of Durham, United Kingdom, and to

(C) 2010 by The University of Chicago. All rights reserved. 0002-9602/2010/11504-0005\$10.00
}

1150 AJS Volume 115 Number 4 (January 2010): 1150-90 
understanding for implementation (Burt 2005; Obstfeld 2005; Uzzi and Spiro 2005). Whereas this brokerage-plus-closure perspective sees innovation as importing and implementing ideas, we offer an alternative conception of entrepreneurship as recombination. In our view, truly innovative ideas - in the first instance, a fresh conceptualization of the problem itself-are not free-floating outside the group.

Instead of importing ideas or information, the challenge is to generate knowledge. It follows that the work of generative recombination requires intense interaction and deeply familiar access to knowledge bases and productive resources, as opposed to long-distance contact and casual access. From this perspective, entrepreneurship, as an enabling capacity, proves productive not so much by encouraging the smooth flow of information or the confirmation of fixed identities but by fostering the generative and productive friction that disrupts the received categories of "business as usual" and enables the redefinition, redeployment, and recombination of resources (Stark 2009). Yet, a simple expansion of cohesive group membership would not be sufficient: recombination requires interaction across diversity.

Therefore, we argue that entrepreneurship in the business-group context is driven by the intersection of cohesive groups where actors have familiar access to diverse resources available for recombination. In making this argument, we draw on Simmel's ([1922] 1964) insight that membership in cohesive groups can overlap. With a method that allows us to identify cohesive-yet nonexclusive-groups, we bring theoretical attention to the distinctive structural position at their intersection. Our concept of structural fold is a theoretical counterpart to Burt's (1992) concept of structural hole with different network properties. Corresponding to our different understanding of the innovation process and the structural basis for it, intercohesion, as mutual participation in multiple cohesive groups, provides the requisite familiarity and diversity for access and for action through a distinctive network topography that is not a summation of brokerage and closure.

We further argue that entrepreneurship has not only structural properties within a synchronic dimension but also dynamic properties along the temporal dimension. Specifically, entrepreneurial structures are not only creative but also likely to be disruptive. Thus, our dual task is to analyze structural features that predict group performance and to analyze whether and how these same structural features contribute to or undermine the continued existence of the group itself.

the Max Planck Institute for the Study of Societies in Cologne for hosting Stark as a visiting fellow while the manuscript was in preparation. Direct correspondence to Balazs Vedres, Central European University, Zrinyi utca 14, 1051, Budapest, Hungary. Email: vedresb@ceu.hu ordcs36@columbia.edu 
American Journal of Sociology

We propose historical network analysis as a new vantage point from which to reexamine the essence or constitution of "groupness" itself. The conventional graph snapshot of network analysis does not distinguish robust and stable collectivities from transitory alignments; it only enables the distinction between denser or sparser network regions. Within that conventional framework, it is tempting to focus only on denser regions as cohesive structures where strong forces of structural determination hold members together. Once we think of groups as histories of cohesion, however, we can loosen the conceptual hold of determining structures and envision groups as sites and tools of agency (Sewell 1992). We can recognize groups despite temporary losses in density. In fact, we often find that the strategic separation between groups within larger units is only recognizable through historical analysis. Thus, our analysis addresses a fundamental sociological question: What is a social group across time in network terms?

Our analysis proceeds through three tests. In the first test, we find that intercohesion is a significant factor explaining outstanding group performance: groups with more structural folds show higher revenue growth. Moving to dynamic models, we find in the second test that structural folding significantly predicts group breakup. Entrepreneurial intercohesion is performance enhancing but comes at the apparent "cost" of group stability. Our findings thus suggest that intercohesion is doubly generative: in the first instance, its creative tensions of familiarity and diversity promote group performance, while in the second instance, these same tensions foster a creative disruption that generates the dispersion of group members who become available for later regrouping.

In a third test, we move from dynamic modeling to historical network analysis to analyze the coherence of groups in their repeated reconstitutions. Do destabilized groups scatter to the winds or do they re-form along patterned lines that would indicate the existence of business groups in the proper sense of larger, historically constituted collectivities? To address this question, we develop the concept of lineages of cohesion as a construct that captures the continuous chains of ancestry of the cohesive nuclear structures in our prior models. Our approach furthers an agenda to develop social sequence analysis (Stark and Vedres 2006). Whereas sequence analysis typically conceptualizes sequences as isolated and linear, sequences of cohesion are conceptualized here as interconnected and branching. In our case, the "kinship structure" of business groups is given by the reproduction and the exchange of members among nuclear groups across "generations" (the years in our study). We find that business groups as larger historical collectivities maintain their coherence through interwoven lineages.

Postsocialist Hungary offers an excellent case for examining organi- 
zational innovation and the historical evolution of business groups. The dislocations and uncertainties facing state-owned enterprises undergoing privatization, new startups, and foreign-owned subsidiaries can hardly be overstated. With the collapse of COMECON (the trading system among Soviet-bloc states) following the demise of the Soviet Union, many firms faced the almost total collapse of their once-guaranteed markets. When the institutional framework for corporate forms was established in 1988, the number of corporations expanded rapidly (from a handful to half a million today). Business networks and business groups emerged quickly as organizational experimentation rapidly gathered speed to locate or generate markets for products of the group and to buffer members from varied uncertainties. Several studies have demonstrated the innovative capacity of postsocialist firms and groups in making use of new corporate institutions, such as cross-ownership, board ties, and holding structures (Stark 1996; Spicer, McDermott, and Kogut 2000).

In this context, the new institution of corporate supervisory bodies and boards of directors offered firms reliable sources of information, access to insider knowledge about successes and failures occurring elsewhere in coping with challenges, and a mechanism for coordinating actions among strategic business allies. Required by corporate law, the institution was entirely novel to Hungarian executives. CEOs and other senior managers whom we interviewed recalled their puzzlement on attending their first board meeting, but they also emphasized how quickly firms grasped the possibility of sharing directors as an opportunity for coordinating strategy.

Our data set documents this process of organizational experimentation and the dynamics of group formation and entrepreneurship. We have collected the names of all economic officeholders in Hungary from 1987 to 2001, defining economic officeholders as all senior managers and members of the boards of directors and supervisory boards of the largest 1,696 companies. With our list of 72,766 names and the exact dates of their tenure on these boards, we can construct the personnel ties connecting these largest firms for each year in our study. Our case reaches back to the very moment when firms could adopt the newly legalized, corporate form. ${ }^{2}$ It includes periods of business uncertainty involving privatization,

\footnotetext{
${ }^{2}$ Our study contributes to historical network analysis using large data sets across relatively long time frames. Padgett and McLean (2006), e.g., develop a multiple network approach to study the genesis of the banking form over some 80 years in Renaissance Florence. Powell et al. (2005) apply a dynamic network approach to understand the emergence of biotechnology, following ties between more than two thousand organizations over a 12-year period. Uzzi and Spiro (2005) examine network properties of cohesion and connectivity among a population of 2,092 people who worked on 474 Broadway musicals from 1945 to 1989 (see also Wuchty, Jones, and Uzzi 2007).
} 
American Journal of Sociology

transformational recession, marketization, the institutionalization of economic regulations, massive foreign direct investment (FDI), as well as three parliamentary elections.

\section{NETWORK STRUCTURES FOR ACCESS AND ACTION}

One prominent feature of business networks is that firms cluster together in cohesive groups. Dense ties among the members of the group, it is argued, provide a basis for trust and a means for coordinating action (Useem 1980; Uzzi 1997). Cohesive ties enable groups to implement projects beyond the capacity of any given firm (Granovetter 2005). The sharing of risk along these ties buffers groups from uncertainty. Because it mitigates the impact of abrupt downturns, risk-spreading in such businessgroup networks lowers the volatility of year-to-year profitability (Lincoln, Gerlach, and Ahmadjian 1996).

Another logic states that business groups might elect to forgo high density within the group in favor of maintaining more weak ties to firms outside the group. Such a strategy of sacrificing density for diversity economizes network resources by reducing the number of redundant ties (Burt 1992). Long-distance ties provide access to more channels of information outside the group, and this diversity provides a basis for greater adaptability. According to this logic, the conservatizing strategy of in-group cohesion is maladaptive. This strategy runs the risk of locking the business group into early successes, a strategy that will quickly become detrimental in a situation of rapid change in which the directionality of disruption cannot be foreseen. The defensive strategy of closing ranks risks the chance of creating a false sense of security at a point when the actual situation does not call for pitting survival and innovation against one another, but for seeking innovation in order to survive.

Recent developments in network analysis suggest a third strategy: in place of strengthening ties within the group or reaching outside it, do both. Some researchers use the terms "cohesion" and "connectivity" to characterize this strategy (Watts 1999; Moody and White 2003; Uzzi and Spiro 2005); others favor the terminology of "closure" and "brokerage" (Burt 2005, 2008; Baum, McEvily, and Rowley 2007). Common to all is the notion of the complementarity of these distinctive network properties, regarded as especially beneficial in cases where the goal is innovation. Brokerage/connectivity provides access to ideas and information but in itself lacks the means for implementation. Closure/cohesion provides the means of coordination but lacks diversity for discovery. Together, they can compensate for the limitations of each; Obstfeld (2005) has labeled these as the "action problem" and the "idea problem." Exemplary of this 
approach is the recent study by Uzzi and Spiro (2005), who demonstrate that the success of Broadway musicals (in which innovation is the ability to produce a "hit") is a function of enough cohesion (the continuity in the composition of the musical "team" from one musical to the next) and connectivity (diversity in composition from one musical to the next).

Our study of business groups in Hungary takes these recent developments as its point of departure. With Burt, Uzzi, and others, we share the notion that entrepreneurship (or, more generally, innovation) is not facilitated by either closure/cohesion or brokerage/connectivity alone. Because we agree that the innovation involves a combination of close familiarity and diversity, we similarly seek to identify specific structural features that promote these social processes. However, we depart from the current consensus by arguing for a perspective on entrepreneurial structures that does not involve a summation of the conventional dichotomies. Instead, as we elaborate theoretically in the following section, we develop a conception of intercohesion, a distinctive network structure built from intersecting cohesive groups.

Because we see entrepreneurship as disruptive as well as creative, we are attentive to the finding of Uzzi and Spiro (2005) that innovation requires some reshuffling of groups. Very stable groups (a Broadway musical formed with the same members who worked together in a previous musical) and highly unstable groups (a musical in which few members had worked together before) are less likely to produce an innovation than groups combining members with prior affiliation and novel affiliations. With this insight in mind, we take the next analytical step: Is there a structural feature that can predict successful performance and also explain the dynamics of group formation and dissolution?

\section{INTERCOHESION}

To address this question, we must first identify the relevant groups in network terms. Our case differs from those of Burt and Uzzi, for whom group boundaries (e.g., the members of a team project, the members of a musical) are given prior to the analysis. Business groups in Hungaryunlike those in East Asian economies where analysts can refer to directories listing the members of Japanese keiretsu or South Korean chaeboldo not exist as named places on the economic landscape.

We adopt a measure of cohesion to identify the components of business groups, using the guiding theoretical principle that cohesive group structures need not necessarily be exclusive. ${ }^{3}$ That is, we are deliberately at-

\footnotetext{
${ }^{3}$ Clustering algorithms used by network analysts typically parse cohesive structures
} 
tuned to the possibilities that network structures can be cohesive and overlap. As Simmel (1964) observed in the Web of Group Affiliations, a person is frequently a member of more than one cohesive group at a given time. For Simmel, such multiple-group membership was a source both of individuation for the person and of social integration for the larger collectivities involved. In our population of firms in Hungary, we might find, for example, a power plant that is linked to other power plants in a cohesive group, while also cohesively tied with power distributors and coal mines, linked to other heavy industry companies in a different cohesive group, and associated in a group with banks.

We develop a concept, intercohesion, to refer to mutually interpenetrating, cohesive structures. Figure 1 illustrates the structure of intercohesion in contrast to brokerage and closure. It also shows the distinctive network position, structural fold, at the intersection. ${ }^{4}$ Actors at the structural fold are multiple insiders, participating in dense cohesive ties that provide close familiarity with the operations of the members in their group. Because they are members of more than one cohesive group, they have familiar access to diverse resources. This combination of familiarity and diversity facilitates the work of recombining resources. As the node that is common to multiple groups, structural folds are resources for the groups themselves. Intercohesion is closure without being closed off; it is generative cohesion without insularity.

Our identification of distinctively intercohesive processes (as opposed to an additive operation of the structure of internal group ties and the structure of external group ties) rests on conceptual differences about entrepreneurship. For the adherents of the additive school, innovation is basically conceptualized as a process of germination: bridging or brokerage ties bring the seeds of ideas and information to the nurturing soil of

into separated communities with a resulting blind spot to multiple group membership. In his article on the social group concept, for example, Linton Freeman asserts that overlapping only occurs between groups from different social contexts (such as work, kinship, and friendship), and once the context is clarified, there is little, if any, overlap (Freeman 1992). We argue that partitioning social networks into disjunctive social groups is artificial, driven more by limitations of methodological vision than by sociological insight. Joint appointments in academic departments constitute an overlap of two or more departmental groups. Nuclear families form as the overlap of maternal and paternal kinship groups. It is not exceptional to participate in more than one circle of friends. A more realist perspective thus acknowledges that social groups can be cohesive and overlapping.

${ }^{4}$ Recent work in social network methodology acknowledges that actual network structures can be composed of overlapping cohesive groups (Moody and White 2003). Our analytical contribution is to recognize that, if cohesive groups can overlap, there is a distinctive structural position at the intersection. That is, from a methodological residual, we point to the intersecting location as a sociological object worthy of theoretical reflection. 


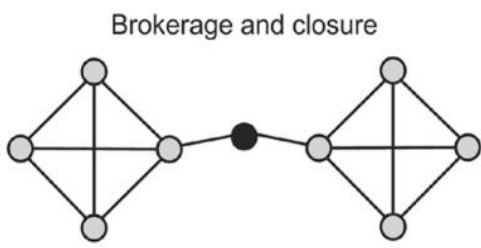

Structural hole

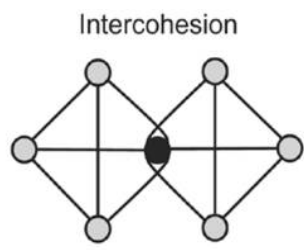

Structural fold

FIG. 1.- The structure of intercohesion in contrast to brokerage and closure

trusting relationships of cohesion. We have no doubts that ideas and information are often vital; our question is whether the activity of productive recombination involves only (or even primarily) resources that can flow or circulate.

With Schumpeter, we conceptualize entrepreneurship as recombination, ${ }^{5}$ a process more complex than the importation and implementation of novel ideas. In our view, the idea problem is itself an action problem. That is, the most innovative ideas are not "out there" in the environment of the group. Instead of waiting to be found, they must be generated (Kogut and Zander 1992). It is one thing to recognize an already-identified pattern, but quite another to make a new association. In this sense, the process of innovation is paradoxical, for it involves a curious cognitive function of recognizing what is not yet formulated as a category (Stark 2009). As John Dewey ([1938] 1998) and the pragmatists argued, it is only in the process of attempting to make a transformation in the world that new problems can even be formulated. Generating novel recombinations is itself a kind of production requiring coordination and cooperation across different communities.

In their study of new product development in cellular telephones, fashion blue jeans, and medical devices, Lester and Piore (2004) demonstrate that each of their cases of radical innovation involves combinations across disparate fields: fashion jeans are the marriage of traditional workmen's clothing and laundry technology borrowed from hospitals and hotels; medical devices draw on both basic life sciences and clinical practice; and cellular phones recombine, in novel form, radio and telephone technologies. They conclude that "without integration across the borders sepa-

\footnotetext{
${ }^{5}$ We are drawing on Schumpeter's definition of entrepreneurship as "the carrying out of new combinations. . . . As a rule, the new combinations must draw the necessary means of production from some old combinations . . . development consists primarily in employing existing resources in a different way, in doing new things with them" (Schumpeter 1934, p. 68). For a neo-Schumpeterian statement in the field of economic growth models, see Weitzman (1998).
} 
rating these different fields, there would have been no new products at all" (Lester and Piore 2004, pp. 14-15). ${ }^{6}$

For us, the telling phrase in this passage is "integration across the borders." Lester and Piore do not refer to "contacts" across borders, for it is not enough for different communities to be in contact. Recombinant innovation requires that they interact. For these reasons, the conventional pairing of access to diversity is insufficient. Deep access for generating new problems, new knowledge, and new capabilities (as opposed to transferring already accepted ideas) requires considerable trust, hence familiarity. Such access can only be achieved through insiders, accepted members of groups. Therefore, we argue that productive recombination at the group level requires familiar access to resources that are not provided by the narrow bandwidth of the slender ties of bridging and brokerage.

Yet these ties cannot be so cohesive as to constitute a single group: to be able to recognize the potential for novel recombinations, entrepreneurship requires access to diverse sets of resources ${ }^{8}$-access that is only possible by being a member of two or more cohesive groups. The distinctive properties of the structural fold provide mechanisms for achieving the diverse familiarities required for recognizing resources and for their productive recombination.

To test these ideas, we correlate the performance of groups and the extent to which they are intercohesive. We expect that groups with more structural folds will perform better than more insular ones.

\footnotetext{
${ }^{6}$ Because innovation, in this view, involves bringing together incompatible traditions, we should not expect that the process will be harmonious. With hindsight, it is easy to see that faded fashion blue jeans are a recombination of workmen's clothing and laundry technology. If we can say that "of course!" cellular phones are the marriage of the radio and the telephone, it is only because, as Lester and Piore show, the respective communities worked from the starting point of their differences.

${ }^{7}$ Bridging can only have as great an impact on cohesive groups as a two-step path length. Members of bridged groups are, at best, friends of friends. The strength of impact between groups is limited by the weak ties that are between them. Whereas actors at the structural hole occupy a brokerage position at the gap and tax flows, intercohesive actors occupy an entrepreneurial position at the overlap and recombine resources.

${ }^{8}$ In examining how different domains of knowledge are brought together to form something new and original, Lester and Piore argue that "ambiguity is the critical resource out of which new ideas emerge. . . . The cell phone emerged in the space created by the ambiguity about whether the product was a radio or a telephone; by playing with that ambiguity, the device became something that was different from either of them" (Lester and Piore 2004, p. 54). Lester and Piore further observe that radio and telephone technologies each claim a distinct commercial and engineering tradition, with the segment of the radio industry from which cellular technology was derived being particularly distinctive, based on two-way radio mounted in police cars and fire engines. "The cultural differences between radio and telephone engineering were deep rooted" (Lester and Piore 2004, p. 17).
} 
Structural Folds

\section{INSTABILITY AND COHERENCE}

Establishing correlations between structures and performance in a crosssectional context leaves unaddressed the question of durability: Are the ties transitory or are they indicative of a sustainable, self-generating pattern? ${ }^{9}$ While testing whether intercohesion is performance enhancing, we further analyze whether this same structure is self-perpetuating or selfdestructive. From a theoretical perspective, structural folds are points of tension where multiple routines of operation and schemas to organize resources are at work. As prominent locations of restructuring agency, such intersecting social structures can be engines of social change from within (Sewell 1992). ${ }^{10}$

Our examination of the role of intercohesion in the dynamics of group evolution stems from our conception of entrepreneurship. As Schumpeter (2003) observed, entrepreneurship, while fostering innovative recombinations, also contributes to "creative destruction." Expressed in network analytic terms, entrepreneurial structures are likely to destabilize groups. As Uzzi and Spiro's (2005) findings suggest, stability in itself is not the most favorable outcome; indeed, some disruption can be beneficial. We therefore test not only whether the creative tensions of intercohesive familiarity and diversity are performance enhancing in the first instance, but also whether these same tensions foster a creative disruption that disperses group members who become available for later regrouping. We expect that recombinant opportunities provided by structural folding will have performance-enhancing effects at the group level. We further expect that these benefits come at the cost of group stability.

Overlapping membership can be disruptive for group coordination, relations of reciprocal trust, and a sense of fairness. Those with multiply

\footnotetext{
${ }^{9}$ Founding statements in the field of network analysis were attentive to issues of duration and temporality. Moreno and Jennings (1937, p. 371), for example, defined cohesion as "the forces holding the individual within the groupings in which they are." At midcentury, Festinger, Schachter, and Back's (1950, p. 164) study of social pressures in informal groups addressed "the total field of forces which act on members to remain in the group" (see McPherson and Smith-Lovin [2002] and Friedkin [2004] for discussion). In this emphasis, they echo Simmel, whose publication in an early issue of the American Journal of Sociology was titled "The Persistence of Social Groups" (Simmel 1898).

${ }^{10}$ By analyzing the dynamics of intersecting business groups, we follow theoretical insights on structure and agency most prominently formulated by William Sewell (1992). Sociological arguments involving structures are typically aimed at explaining stability, closure, and reproduction. To explain social change, the opening of new possibilities, and ruptures in social reproduction, sociologists look for evidence of external shocks, forces from the outside. Sewell argues for a conception of structure that enables change from within. He argues that the intersection of structures, social groups in our case, helps explain change without reference to external impacts.
} 
cohesive attachments might seem to follow strategies that are not transparent to those with single membership, a situation that may hinder coordination. In the face of the ambiguous loyalties of the structural fold, other members might suspect they are being exploited or manipulated; the lack of commitment and time devoted by those with multiple memberships to a given group might lead to group-level dysfunction, perhaps even fracture and fragmentation. Intercohesion, we therefore expect, will be negatively correlated with cohesive group stability.

If intercohesion represents a process of generative disruption, are business groups forced to choose between seeking stability or high performance? A historical perspective suggests an alternative, whereby business groups keep fragmentation within manageable limits. Viewed in a dynamic year-to-year time frame, we expect to find a system of membership turnover that appears in considerable flux. But the very notion of the business group (and the literature on long-lasting business groups) suggests some degree of coherence that endures longer than simply from one year to the next (Mizruchi and Stearns 1988; Granovetter 2005). In other words, can considerable instability be squared with the concept of business group as a coherent entity? To address this question, we apply a historical analysis to complement our dynamic (year-to-year) analysis.

In our view, the concept of the business group is not simply a network analytic construct; it is a historical network construct. From that perspective, cohesive group structures in a synchronic frame are the building blocks of the larger collectivity constituting the business group within a longer historical time frame. These nuclear groups can be connected across time to other groups through member exchange. By tracing these ties, we can construct a historical-sociological object shaped by patterns of common ancestry. In other words, we turn from nuclear groups to the broader "kinship structures" of business organization.

To identify the patterns of these kinship structures, we develop a concept of lineages of cohesion through which we trace chains of ancestral continuity reaching as far back in time as 12 years. Our intuition is that nuclear groups that share an ancestry might stay close to one another, connected by the intercohesive sharing of members and a common, repeatedly interwoven line of descent (Brudner and White 1997; White and Johansen 2005). A common ancestry makes group formation easier because routines of collaboration are already familiar. This familiarity facilitates the emergence of structural folding: groups that share an ancestry might be less likely to have radically different routines and cultures of collaboration, thus reducing the attendant coordination costs of structural folding.

We find that some business-group lineages operate through a single line of succession. Yet just as often, we find more complex lineages, ones that 
branch in one "generation," reconsolidate in the next, and repeat these processes of exploration and reconsolidation over successive years, with structural folds playing a decisive role in this splitting and reweaving. Groups connected by member exchange operate as larger collectivities that absorb and hence limit the scattering of members from destabilized groups and thus mitigate the disruptions caused by intercohesion. Instead of becoming dispersed across the full range of groups in the entire economy, groups break up to rejoin with others near them, thereby regrouping their resources in a fresh yet familiar combination. Instability thus becomes member recombination. In short, instability is consistent with patterned coherence: business groups cope with the uncertainties of their environment by keeping group fragmentation within manageable limits.

\section{DATA AND METHODS}

Data

The data set that we have assembled includes the complete histories of personnel ties among the largest enterprises in Hungary spanning the years 1987-2001. We define large companies as those listed in the annual ranking of the top 500 firms (based on revenue) for any year from 1987 to 2001. Our inclusion rule results in a population of 1,696 firms. This population of firms represents more than a third of employment, about half of Hungarian GDP, and almost all export revenues (Figyelö 2002).

We define economic officeholders as senior managers and members of the boards of directors and the supervisory boards of these large enterprises. Personnel data on economic officeholders were transcribed directly from the official files of the 20 Courts of Registry where Hungarian firms are obliged to register information about ownership and personnel. These registry files contain the names and home addresses of all managers who have signatory rights (entitled to sign documents that become legally binding on the firm). The files also list the members of the board of directors and the supervisory board. For each firm, we have recorded the names of all signatories and board members who held office in the period studied, as well as the exact dates when they assumed and left office. Our data set on economic officeholders contains 72,766 names.

Beyond economic officeholders, we have also collected the names of all political officeholders in Hungary during this same period. For the years 1990-2001, we define political officeholders as every elected politician from the prime minister, to the members of Parliament, to the mayors of all municipalities, including the top three levels in the hierarchy of the national government ministries (encompassing cabinet ministers and their political and administrative deputies). For the period prior to free elec- 
tions, we define political officeholders as all members of the Politburo and the Central Committee of the Hungarian Socialist Workers Party, as well as government ministers and their deputies. ${ }^{11}$ This covers the political elite under state socialism. For all periods, we record the party affiliation of each officeholder and the exact dates of tenure in office. Our data set on political officeholders covering the period 1987-2001 contains 16,919 names. By merging the lists of economic and political officeholders, we can precisely identify, for any given enterprise in any given month, whether that company had an economic officeholder who was also a current or former political officeholder affiliated with a particular political party.

We define two companies as having a personnel tie if a manager or a board member of one company sits on the board of another company. This means that we are using the one-mode projection (ties between firms) of the original two-mode data (ties between board members and boards) (Breiger 1974). This operation entails losing data in the technical sense, as a completely connected triangle of firms in the one-mode projection can arise from different configurations in the two-mode network (for example, one director sitting on all three boards, or three directors sitting on two boards each). We have two main reasons for analyzing the onemode projection despite loss of affiliational detail.

The first consideration is that personnel ties are vehicles for establishing business alliances (Mizruchi 1996; Burris 2005). Actors in the postsocialist Hungarian business setting view corporate board directors as representatives of government agencies, parties, or other partnering enterprises. It is through such personnel ties that firms forge alliances with other organizations. In our interviews, CEOs and other senior managers repeatedly told us about how they are attentive to board composition. In speaking, for example, with the CEO of a key company within a business group that we had identified, we asked

Q. How are boards of directors important?

A. It was necessary to have board interlocks in order to work out the problems. My predecessor here was only CEO, and without any board interlocks, he didn't have a chance.

\footnotetext{
${ }^{11}$ Data on political and government officeholders were collected from the National Bureau of Elections (which holds records on all elected political officeholders) and from the Hungarian News Agency (which maintains records on all government officials entering or exiting office). Whereas the Communist Party's Central Committee is analogous to the parliament of the subsequent democratic period, the Politburo was akin to the role of the government in the later period. Names of political officeholders in these years from 1987 to 1989 were gathered from a comprehensive CD-ROM publication (Nyírő and Szakadát 1993).
} 
Q. What about outside board members?

A. For our partners, it is important who they see on our board. And for me, I have trouble when I see unknown persons on a board. It sends a bad message. The business could be a little strange.

Similarly, with the chief strategic officer of one of Hungary's largest banks, we opened the interview by displaying the charts we had created showing the history of the bank's personnel ties to other firms. We asked whether he might tell us why the bank had made such and such an affiliation. Pausing for effect and looking directly in our eyes, he answered with cold emphasis: "That's my business." We swept the papers aside and asked if we might speak in more general terms. He stated that the reasons for making these ties were deeply proprietary, and he went on to elaborate in detail how it was indeed his job, his business, to monitor the composition of boards to detect the making and breaking of interorganizational alliances in the formation of business groups.

Our second consideration is that, although the methods and techniques to deal with one-mode and two-mode networks are sharply different, the substantive differences between the two kinds of networks are less pronounced. Networks that are originally collected as one-mode often have an underlying two-mode substrate: a network of friendship ties might reflect a two-mode affiliation network of people and friendship circles (Watts 2004). In the business context, the system of personal affiliations with boards might be thought of as a substrate to business-to-business alliances. $^{12}$

We record personnel ties as symmetrical, with a starting and ending date for each tie. The models in this study use an annual time resolution, with personnel ties recorded at the last day of each year. We define a firm as having a political affiliation when one of its economic officeholders is also a current or former political officeholder, ${ }^{13}$ and we record the party

\footnotetext{
${ }^{12}$ While considerable advances have been made recently in developing methods for two-mode networks (Skvoretz and Faust 1999; Field et al. 2006), group detection routines developed for two-mode data start out from the assumption that groups are nonoverlapping (Field et al. 2006, p. 105) - an assumption that we are fundamentally questioning is this article.

${ }^{13}$ The motivation to include former as well as current political officeholders comes from our interviews with managers of large firms. As one CEO noted: "In Hungary there is no such thing as an ex-politician. Once a politician, always a politician."
} 
affiliation of that political officeholder as the party affiliation of the firm. Political affiliations are thus personnel ties connecting firms and parties. ${ }^{14}$

For each firm, we also collected data on its annual revenues, capitalization, employment, industrial classification, privatization history, and types of owners (state, domestic private entity, or foreign owner).

\section{Identifying Cohesive Groups with the Clique Percolation Method}

To identify cohesive groups, we adopt a method that starts from cohesive localities, recognizes groups independent of the global network environment, and identifies structural folds. We use the clique percolation method (CPM) developed by physicists to uncover the overlapping community structure of complex networks (Palla et al. 2005), a method recently demonstrated as a suitable tool to analyze the evolution of cohesive groups (Palla, Barabási, and Vicsek 2007).

The CPM starts from a clique of $k$ nodes, a $k$-clique. In social network analysis, cliques were often rejected as a useful metric of cohesion because they can highly overlap with other cliques. For example, a network of 10 nodes can have two cliques of nine that have eight nodes at their overlap. The standard way of resolving this problem was to parse cohesion by recording the number of times two nodes coparticipated in cliques. Use of this similarity as input for cluster analysis yielded exclusive, nonoverlapping cohesive regions in the network (Wasserman and Faust 1994).

Whereas standard modeling procedures partition cohesion at the global network level by counting similarities at the node level, CPM is grounded in strictly local properties at the clique level. Instead of regarding clique overlap as a problem to overcome, it regards clique overlap as the starting point for identifying cohesion. (See the appendix for details on this method.)

Although developed by physicists, the method improves standard approaches in social network analysis and resonates with new departures from the conventional models. Most important for our purposes, a group identified by the CPM method can overlap with another group. Thus, CPM is in line with Everett and Borgatti (1998), who recognized the limitations of forced partitioning in various algorithms and pointed to the

\footnotetext{
${ }^{14}$ We do not record a personnel tie between two firms when the tie is created by a political officeholder. Two firms might invite the same politician or ministry official to sit on their boards, not because they wish to establish a tie to each other, but because they seek a political and/or government connection. Political affiliations are about personnel ties between parties and firms and not between firms. Including a personnel tie between these firms would introduce noise in the data that would potentially blur the patterns of personnel ties created to foster business collaboration.
} 
utility of clique adjacency as a theoretical solution. ${ }^{15}$ By relaxing clique membership in favor of clique adjacency, hence capturing group overlaps, CPM achieves greater sociological realism that allows for closer approximation to the notion of community than does the concept of a sociometric clique. In a social community-unlike in a network clique-everyone is not necessarily connected to everyone else. We use CPM to identify groups in all years in our data set from 1987 to 2001.

\section{GROUP PERFORMANCE}

If intercohesive recombination contributes to entrepreneurship and innovation at the group level, intercohesive groups should outperform exclusive ones. Does intercohesion contribute to group performance? To answer this question, we first need to identify a suitable metric of performance and then isolate the contribution of intercohesion to performance.

Profitability, although a widely used indicator of performance, has questionable validity in the postsocialist setting. With high taxes and changing government regulations, profits can easily be manipulated-or, euphemistically speaking, "optimized"-_epending on prevailing regulations. At a time when most firms were undergoing restructuring programs, profitability was not a practical metric to gauge firm performance. Instead of turning immediate profits, the key to survival was obtaining and keeping markets and thus securing revenues. We choose therefore to focus on revenue dynamics.

We consider the simplest test to be the correlation between intercohesion at year $t$ and revenue growth from year $t$ to $t+1$. For a given group in a given year, intercohesion is measured by the number of structural folds, that is, the number of groups with which that given group overlaps. Revenue growth is the growth rate at group level measured in real terms (corrected for inflation). This correlation between intercohesion and revenue growth is significant $(P=.049)$ and positive, although weak $(R=.088)$. This indicates that groups with more structural folds grew slightly faster.

Does higher revenue growth in groups with intercohesion accrue only at the structural fold? If intercohesion operates similarly to brokerage, we expect that firms at the intersection will see a faster increase in their revenues, compared to firms with only one membership. To answer this question, alongside computing the correlation between intercohesion and

${ }^{15}$ As Everett and Borgatti demonstrate, a network of 21 nodes can have as many as 2,187 cliques. The prevalence of overlapping in this case is clearly a far departure from what we would think of as meaningful group processes. 
revenue growth at the group level, we also computed the correlation between the number of cohesive group memberships and revenue growth at the individual level. This Pearson correlation is not statistically significant $(R=.039 ; P=.127)$, which indicates that the benefits of intercohesion are realized at the group level and do not appear distinctly at the level of the individual firms occupying the structural fold. ${ }^{16}$ The mechanisms of structural folding seem to differ from gatekeeping and brokerage, where benefits—additional revenue-generating possibilities—would accrue at the gatekeeping firm spanning the two groups.

To further test the relationship between growth and intercohesion and to isolate this relationship from other predictors of revenue growth, we construct multivariate models. Our goal is to evaluate whether there is a significant relationship between intercohesion and growth even if we introduce variables of intracohesive processes (such as group size or homophily), extracohesive processes (primarily those of brokerage and bridging), and control variables, such as industry composition and efficiency.

For each group in our data set, we have a score of real revenue growth. From this continuous variable, we construct two categorical dependent variables capturing the distinctive processes of revenue decline and growth. Groups that are more entrepreneurial should achieve higher performance, but entrepreneurship does not guarantee performance. Thus, we also expect that more entrepreneurial groups are not buffered from declining performance.

Revenue decline records whether the revenues of the group declined during the year in question. High revenue growth records whether the group belonged in the most successful $25 \%$ of groups in the overall sample (revenues for this top quartile corresponded to at least $8 \%$ annual growth, controlling for inflation). We have two reasons for transforming our ratioscale variable into two categorical variables. The technical reason is that the distribution of revenue growth is highly skewed - there are many groups with modest growth and few with extremely high growth. The second reason is substantive-we believe that the predictors of preventing revenue loss and the predictors of achieving high performance are distinct.

As table 1 reports, our first independent variable is intercohesion: the number of structural folds. We expect intercohesion to lower the probability of revenue decline and to increase the probability of high revenue growth.

\footnotetext{
${ }^{16}$ The structural fold is a property of the group and, as such, its benefits accrue to the group. To take an example from the academic setting: at Columbia University, Charles Tilly benefited from his joint appointments in history and sociology. But we could also observe that the sociology department was different-and benefited as a departmentbecause it had a member who was an insider in another cohesive group.
} 
TABLE 1

DEsCRIPTIVE Statistics

\begin{tabular}{|c|c|c|c|c|}
\hline Independent Variable & Mean & $\mathrm{SD}$ & Min & Max \\
\hline Intercohesion $\ldots \ldots \ldots \ldots \ldots \ldots \ldots \ldots$ & 2.707 & 2.746 & .000 & 19.000 \\
\hline Group stability from $t$ to $t+1 \ldots \ldots \ldots$ & .514 & .259 & .120 & 1.000 \\
\hline Group stability from $t-1$ to $t \ldots \ldots \ldots$ & .438 & .282 & .000 & 1.000 \\
\hline Revenue growth from $t$ to $t+1 \ldots \ldots$ & 1.587 & 3.945 & .170 & 63.190 \\
\hline Negative growth from $t$ to $t+1 \ldots \ldots$ & .544 & .499 & .000 & 1.000 \\
\hline Top quartile growth from t to $t+1 \ldots$ & .249 & .428 & .000 & 1.000 \\
\hline \multicolumn{5}{|l|}{ Intracohesive processes: } \\
\hline Group size $\ldots \ldots \ldots \ldots \ldots \ldots \ldots \ldots$ & 4.661 & 1.168 & 4.000 & 11.000 \\
\hline Capital size of the largest firm ..... & 9.355 & 1.241 & 1.000 & 10.000 \\
\hline Size difference $\ldots \ldots \ldots \ldots \ldots \ldots \ldots$ & 1.507 & 1.650 & .000 & 9.000 \\
\hline Financial members $\ldots \ldots \ldots \ldots \ldots$ & .722 & 1.101 & .000 & 8.000 \\
\hline Industry homogeneity & .409 & .317 & .000 & 1.000 \\
\hline \multicolumn{5}{|l|}{ Extracohesive processes: } \\
\hline Brokerage $\ldots \ldots \ldots \ldots \ldots$ & 19.242 & 10.870 & .000 & 44.000 \\
\hline Bridging ties $\ldots \ldots \ldots \ldots \ldots$ & 11.217 & 11.806 & .000 & 72.000 \\
\hline State-owned proportion $\ldots \ldots \ldots \ldots$ & .255 & .267 & .000 & 1.000 \\
\hline Foreign-owned proportion $\ldots . . . \ldots$. & .253 & .231 & .000 & 1.000 \\
\hline Politicized proportion $\ldots \ldots \ldots \ldots \ldots$ & .223 & .182 & .000 & .800 \\
\hline Political $\operatorname{mix} \ldots \ldots \ldots \ldots \ldots \ldots \ldots$ & .260 & .439 & .000 & 1.000 \\
\hline Governing party tie $\ldots \ldots \ldots \ldots \ldots$ & .910 & 1.007 & .000 & 5.000 \\
\hline \multicolumn{5}{|l|}{ Controls: } \\
\hline Year...$\ldots \ldots \ldots \ldots \ldots$ & 96.594 & 2.903 & 89.000 & 101.000 \\
\hline Group age $\ldots \ldots \ldots \ldots \ldots \ldots \ldots$ & 2.817 & 1.820 & 1.000 & 11.000 \\
\hline Newly formed group $\ldots \ldots \ldots \ldots \ldots$ & .113 & .317 & .000 & 1.000 \\
\hline Labor efficiency $(\log ) \ldots \ldots \ldots \ldots \ldots$ & .700 & .530 & -.550 & 2.824 \\
\hline Capital efficiency $(\log ) \quad \ldots \ldots \ldots \ldots$ & -2.636 & .652 & -4.513 & .447 \\
\hline Sum of revenues $(\log ) \ldots \ldots \ldots \ldots$ & 4.067 & .701 & 2.400 & 5.701 \\
\hline \multicolumn{5}{|l|}{ Industry: } \\
\hline Energy & .048 & .213 & .000 & 1.000 \\
\hline Mining $\ldots \ldots \ldots \ldots \ldots \ldots \ldots \ldots \ldots$ & .015 & .121 & .000 & 1.000 \\
\hline Chemical $\ldots \ldots \ldots \ldots \ldots \ldots \ldots \ldots$ & .151 & .466 & .000 & 4.000 \\
\hline Metallurgy $\ldots \ldots \ldots \ldots \ldots \ldots \ldots$ & .061 & .253 & .000 & 2.000 \\
\hline Heavy industry $\ldots \ldots \ldots \ldots \ldots \ldots$ & .400 & .836 & .000 & 5.000 \\
\hline Light industry $\ldots \ldots \ldots \ldots \ldots \ldots$ & .331 & 680 & .000 & 3.000 \\
\hline Wood and textile $\ldots \ldots \ldots \ldots \ldots$ & .140 & .396 & .000 & 3.000 \\
\hline Food industry $\ldots \ldots \ldots \ldots \ldots \ldots$ & .627 & 1.104 & .000 & 8.000 \\
\hline Construction $\ldots \ldots \ldots \ldots \ldots \ldots \ldots$ & .258 & .878 & .000 & 6.000 \\
\hline Wholesale $\ldots \ldots \ldots \ldots \ldots \ldots \ldots$ & .421 & .655 & .000 & 4.000 \\
\hline Retail $\ldots \ldots \ldots \ldots \ldots \ldots \ldots \ldots \ldots$ & .367 & .659 & .000 & 4.000 \\
\hline Transport $\ldots \ldots \ldots \ldots \ldots \ldots \ldots \ldots$ & .102 & .319 & .000 & 2.000 \\
\hline Services $\ldots \ldots \ldots \ldots \ldots \ldots \ldots \ldots$ & .650 & .869 & .000 & 4.000 \\
\hline
\end{tabular}


American Journal of Sociology

Our second set of independent variables represents intracohesive processes. The first variable is group size, the number of firms in the group. Similar to Simmel's sociology of numbers, we expect that larger groups will have different revenue dynamics than smaller ones have, as it is less likely that a large group achieves extraordinary growth. The second variable registers processes of homophily based on homogeneity in the industry profile. ${ }^{17}$ We measure this industry homogeneity by the numerical difference between the first- and second-most prominent industry categories in the group. If the group is entirely made up of one industry, this variable is equal to one. If there are two equally represented industry categories, this variable is equal to zero. Three other variables refer to processes of economic power and dominance in stabilizing or destabilizing the group. Size of the largest firm is measured in deciles of capitalization, ranging from 1 (smallest firms) to 10 (largest firms). The expectation is that powerful economic players can hold a group together (Thye, Yoon, and Lawler 2002). To assess the effects of relative economic dominance, we record size difference as the size-decile difference between the largest and second-largest firms in the group. A larger value indicates a more clearly dominant player in the group in terms of size. Whereas Thye et al. (2002) expect that the equality of power fosters group stability, Gould's (2003) formulation would predict that equality of power would lead to conflict and group breakup. The variable financial members records the number of financial firms that are members of a given group. Following Mizruchi and Stearns (1988), we expect groups with financial members to have inferior performance.

Our third set of independent variables represents extracohesive processes. For each group, we record being brokered as the number of other groups to which the group is connected by an intermediary. We also record bridging ties, the number of other groups that are reachable with a direct tie from the group in question. These variables represent brokerage as recently reformulated by Ronald Burt (Burt 2005). Whereas Granovetter (1973) would expect that groups with bridging ties will have higher performance, we are also attuned to the possibility that being brokered has negative implications on performance (Fernandez-Mateo 2007).

\footnotetext{
${ }^{17}$ Homophily has been shown to be an important factor contributing to cohesive affiliation (McPherson, Smith-Lovin, and Cook 2001). McPherson and Smith-Lovin (2002, p. 13) define homophily as "the positive relationship between similarity (on almost any dimension) and the probability that two people will have a network connection between them." Although McPherson has not studied business groups, the most pertinent dimension of similarity in this context is homogeneity of industry profile. If homophily is operating among our Hungarian firms, cohesive groups concentrated in the same industry should be more likely to exhibit stability than those of greater industrial heterogeneity.
} 
Among extracohesive processes, we also consider the reach of the group into the political field. This dimension is salient because our case involves profound economic dislocation in the context of a simultaneous political transformation (Stark and Bruszt 1998). Business groups are seen as especially suitable vehicles for political affiliation in such emerging markets (Khanna and Rivkin 2001). We include three variables to tap various aspects of these processes. Politicized proportion records the proportion of group-member firms having party affiliations through personnel ties. A group exhibits political mix when we find affiliations to parties on both the left and the right. Governing party ties records a group having a political affiliation to a currently governing party.

The final variables in this set of extracohesive processes involve links to owners outside the group. ${ }^{18}$ State-owned proportion records the proportion of group members for which the state is a significant owner. Foreign-owned proportion similarly records the proportion of group members in foreign ownership.

As control variables, we include year as well as group age, defined as the average number of years that pairs of group members have spent in groups together. We include specific industry categories, an indicator of whether the group was newly formed by firms that had not belonged to any groups in the previous year, labor efficiency (measured as revenues over number of employees), and capital efficiency (measured as revenues over capitalization). To correct for skewness of the distribution on these latter two variables, we take the logarithms.

Both models - the model of declining performance and the model of high performance-pass the Hosmer-Lemeshow test for fit and Pregibon's link test of model specification. Tolerance and variance-inflation factors were within conventional bounds for all independent variables, indicating that multicollinearity should not be a concern. To test for sensitivity in defining the cut point of high performance at the top 25\%, we ran the high-performance model with dependent variables representing the top $30 \%, 20 \%, 15 \%, 10 \%$, and $5 \%$ of revenue growth. In all of these models, the sign and significance of the intercohesion coefficient were the same.

In table 2, we see that intercohesion does not buffer against revenue decline, but it is a strong predictor of high growth. It should be kept in mind that, by definition, all the groups we examine in table 2 are cohesive.

\footnotetext{
${ }^{18}$ Our data set contains detailed information about firms' ownership structure. For each firm, we can record whether it has sizable state ownership and sizable foreign ownership, as well as details in the timing of any changes in such ownership. Our definitions of significant state and foreign ownership follow procedures detailed in Stark and Vedres (2006).
} 


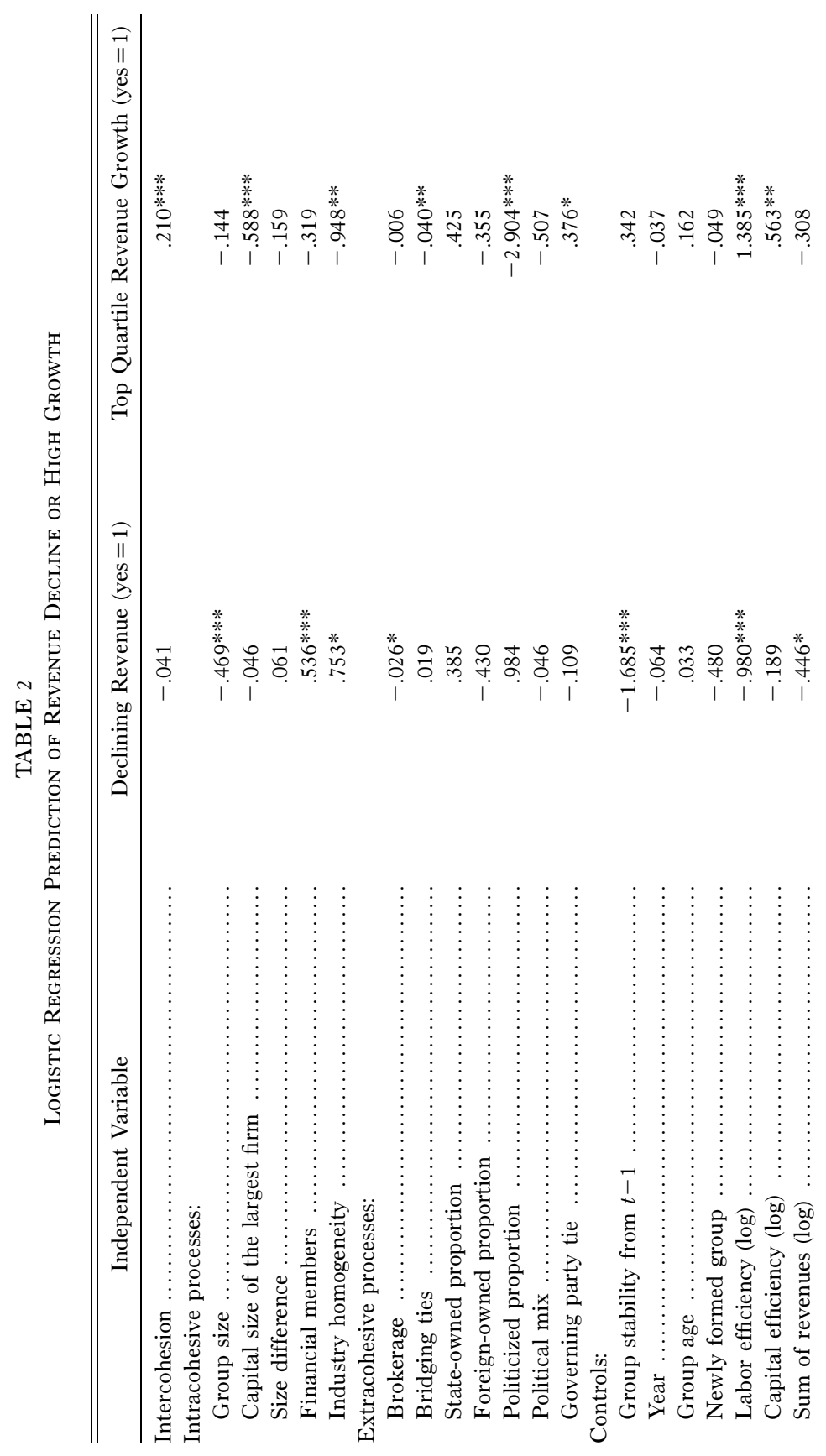

1170 


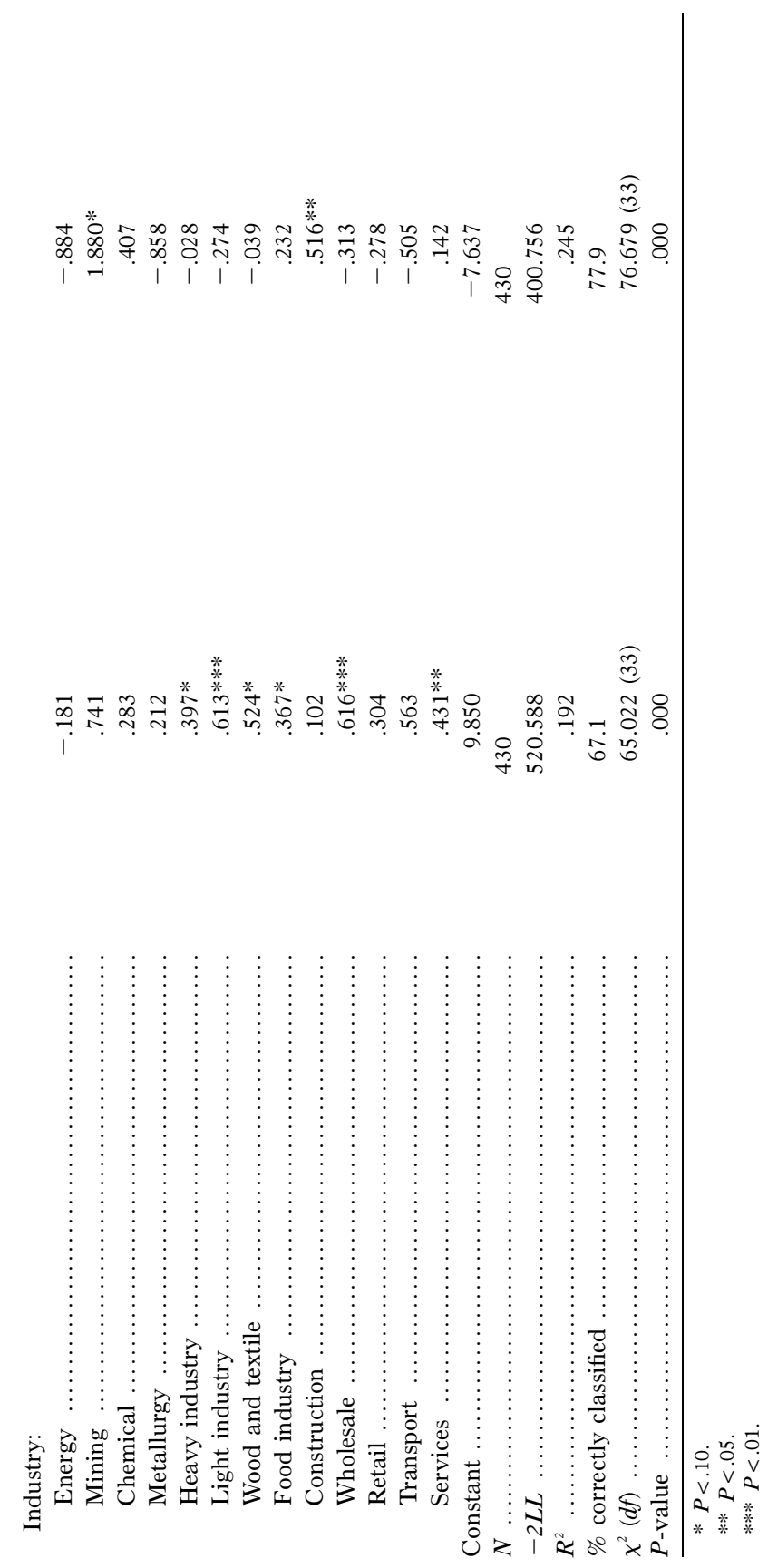

1171 
Intercohesive groups outperform their counterparts, who lack this ambiguous yet recombinative advantage.

Turning to intracohesive variables, we see that larger group size makes decline less likely without contributing to growth. For business groups, there is safety in numbers-smaller groups are more at risk of decline. Having a dominant member of large size makes it more difficult for a group to achieve high growth, probably because for large firms a high rate of growth means a large increase in revenue volume. Homophily is a disadvantage. Industry homogeneity increases the probability of decline and decreases the probability of high performance. Groups of more heterogeneous composition are advantaged. This does not apply, however, to groups that include members from finance. Groups with financial members are significantly more likely to face declining revenues. This result might not be surprising to scholars who study business groups: ties to banks are often associated with financial troubles and decreasing performance.

Looking at personnel ties reaching to other business groups, we see that effects on performance diminish as distance increases. Groups with more two-step ties to other groups (mediated through brokers) are slightly less likely to decline but show no advantage in high performance. Groups with ties at the closest reach (not even one step away but established through structural folding) outperform groups that are exclusive, regardless of how intensively or extensively they are embedded. The number of bridging ties to members of other groups decreases the probability of high performance. Bridging ties-circuits for the circulation of ideas-do not contribute to group success. This starkly contrasts the positive contribution of intercohesion. This finding underscores the importance of the entrepreneurial generation of ideas through recombination, as opposed to the reliance on imported ideas from other areas of the network.

Playing party politics is a tricky business. While political contacts do not offer protection against decline, only the most narrow, highly targeted strategy has payoffs. More politicized groups have little chance of achieving high growth. Groups that are overly committed to a party put the trust of their business partners in jeopardy. Groups can only benefit from party politics when they have a tie to a currently governing party.

Intercohesion and group stability operate as mirrored opposites. Group stability buffers groups from revenue decline and does not contribute to top quartile revenue growth. Stability in group membership enables reciprocity, solidarity, and mutual assistance to act as a kind of safety net, thereby preventing severe market loss in the group. But trust and improved communication within the group are not assets that stimulate high levels of growth: stability in itself can be a conservatizing closure. 
Structural Folds

\title{
INTERCOHESION AND GROUP STABILITY
}

Having analyzed how intercohesion is related to group performance, we turn to questions of group stability. To define and measure group stability, we refer to Simmel's article "Persistence of Social Groups," in which he argues that it is meaningful to speak of group identity, despite shifting membership and low institutionalization, if there is some membership continuity in contiguous stages:

\begin{abstract}
We may express this schematically as follows. If the totality of individuals or other conditions in the life of the group is represented by $a, b, c, d, e$ and in a later moment by $m, n, o, p, q$, then we may nevertheless speak of the persistence of identical selfhood if the development takes the following course: $a, b, c, d, e-m, b, c, d, e-m, n, c, d, e-m, n, o, d, e-m, n, o, p, e-$ $m, n, o, p, q$. In this case, each stage is differentiated from the contiguous stage by only one member, and at each moment it shares the same chief elements with its neighboring moments. (Simmel 1898, pp. 670-71)
\end{abstract}

We draw on this insight in our analysis of group stability. For the first year of our data set, we use CPM to identify each of the cohesive groups of firms (e.g., cohesive group 1 is composed of firms $a, b, c, d, e$; cohesive group 2 is composed of $f, g, h, i, j$; and so on). For the second year, we identify the cohesive groups existing at that time. (Following Simmel's lead, we can call them $f, b, c, d, e ; a, g, h, i, j ; v, w, x, y, z$; and so on.) Because network formation is slow at first, and the number of groups appearing at the very beginning is only very small, we modify Simmel's scheme. Instead of simply following the first established groups, we identify all the groups that exist from 1987 to 2001. That is, we identify and record, for each year, all of the cohesive groups that exist in that year. By observing the composition of all groups in $t_{1}$ and those in $t_{2}$, we can record the proportion of the members of any given group that remained cohesively tied - which is our metric of stability - for all pairs of years.

To measure the stability of groups, we record the flow of members between all groups in adjacent years. A group is completely stable from one year to the next if all members of the group identified in the first year appear together in a group in the next year. At the other extreme, a group dissolves if none of the members at $t_{1}$ appear in any groups at $t_{2}$. Between these extremes, a group at $t_{1}$ can split into segments of various sizes that are present in groups at $t_{2}$. To measure such intermediate levels of stability, we score the average size of the pieces from $t_{1}$ that appears in groups at $t_{2}$, thereby normalizing for the size of the source group.

To test whether intercohesion has its own predictive power in the context of competing explanations, we use a multivariate regression model, with group stability as the dependent variable. The independent variables are the same as those that we used in our models of group performance. 
We find a negative correlation between intercohesive ties and group stability. The mean correlation across all years is -0.55 , ranging from -0.37 to -0.70 . This regression model passed Pregibon's link test of model specification; tolerance and variance-inflation factors were within conventional bounds for all independent variables: multicollinearity should not be of concern. Table 3 presents the results of our regression models predicting group stability.

We see that multiple membership ties of intercohesion decrease group stability. In other words, groups with more structural folds are more likely to break up and, when they do, to break up into smaller fragments. This finding suggests that structural folding stresses the fabric of cohesion. Actors who are ambiguously committed produce destabilizing tensions inside these groups.

Of the intracohesive processes, only group size is relevant: larger groups are less stable. Of the various extracohesive linkages, only two are relevant to group stability: brokerage and state ownership. Largely as a consequence of the privatization process, state ownership destabilizes groups. This reorganization erodes the stability of groups with state-owned firms.

The number of brokered ties to other groups is significantly correlated with decreased group cohesion, a finding that suggests that brokers adversely affect the structures they exploit. This finding is in line with the idea that the price of brokerage is borne by those who are connected by the broker (Fernandez-Mateo 2007). In addition to material losses, our findings show another externality of brokerage: the erosion of brokered structures. This structural erosion can eventually diminish the opportunities of brokerage themselves.

Among the control variables, we are not surprised to find that group stability in the preceding year is related to stability in the current year. Group stability has inertia. We also find a positive trend toward greater group stability leading out of the postsocialist period-groups are more stable in the later years. Whereas newly formed groups without a prehistory of cohesion are stable in the first year of their existence, there is a slight disadvantage to old groups.

Groups with higher labor efficiency are more stable, while groups with higher capital efficiency are less stable. A group with a high amount of capital and few employees is much more stable than a group with low capitalization and many employees. This latter type of group was the typical target of reorganization, which disrupted group continuity. In addition, several industry categories are significant and feature varying levels of group stability when compared with the reference category of agriculture.

To summarize, we found that structural folding is disruptive: groups in which membership is not exclusive suffer a loss of stability. Interpen- 
TABLE 3

Linear Regression Prediction of Group Stability

\begin{tabular}{|c|c|}
\hline Independent Variable & Group Stability \\
\hline Intercohesion $\ldots \ldots \ldots \ldots$ & $-.018 * * *$ \\
\hline \multicolumn{2}{|l|}{ Intracohesive processes: } \\
\hline Group size $\ldots \ldots \ldots \ldots \ldots \ldots \ldots \ldots \ldots \ldots \ldots \ldots$ & $-.028 * *$ \\
\hline Capital size of the largest firm $\ldots \ldots \ldots$ & -.009 \\
\hline Size difference $\ldots \ldots \ldots \ldots \ldots \ldots \ldots \ldots$ & .010 \\
\hline Financial members $\ldots \ldots \ldots \ldots \ldots \ldots$ & .006 \\
\hline Industry homogeneity $\ldots \ldots \ldots \ldots \ldots \ldots$ & .029 \\
\hline \multicolumn{2}{|l|}{ Extracohesive processes: } \\
\hline Brokerage $\quad \ldots \ldots \ldots \ldots \ldots \ldots \ldots \ldots \ldots$ & $-.008 * * *$ \\
\hline Bridging ties $\ldots \ldots \ldots \ldots \ldots \ldots \ldots \ldots$ & .001 \\
\hline State-owned proportion $\ldots \ldots \ldots \ldots \ldots$ & $-.078 *$ \\
\hline Foreign-owned proportion $\ldots \ldots \ldots \ldots \ldots$ & .061 \\
\hline Politicized proportion $\ldots \ldots \ldots \ldots \ldots \ldots$ & .021 \\
\hline Political mix $\ldots \ldots \ldots \ldots \ldots \ldots \ldots \ldots \ldots \ldots \ldots$ & .004 \\
\hline Governing party tie $\ldots \ldots \ldots \ldots \ldots \ldots$ & .003 \\
\hline \multicolumn{2}{|l|}{ Controls: } \\
\hline Group stability from $t-1$ & $.204 * * *$ \\
\hline Year $\ldots \ldots \ldots \ldots \ldots \ldots \ldots \ldots \ldots \ldots \ldots \ldots$ & $.023 * * *$ \\
\hline Group age $\ldots \ldots \ldots \ldots \ldots \ldots \ldots \ldots \ldots$ & $-.013 *$ \\
\hline Newly formed group $\ldots \ldots \ldots \ldots \ldots \ldots$ & $.127 * * *$ \\
\hline Labor efficiency $(\log ) \ldots \ldots \ldots \ldots \ldots$ & $.037 *$ \\
\hline Capital efficiency $(\log ) \quad \ldots \ldots \ldots \ldots \ldots$ & $-.033 * *$ \\
\hline Sum of revenues $(\log ) \ldots \ldots \ldots \ldots \ldots$ & .004 \\
\hline \multicolumn{2}{|l|}{ Industry: } \\
\hline Energy $\ldots \ldots \ldots \ldots \ldots \ldots \ldots$ & -.041 \\
\hline 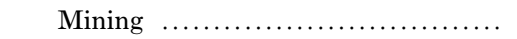 & .086 \\
\hline Chemical $\ldots \ldots \ldots \ldots \ldots \ldots \ldots \ldots \ldots$ & .032 \\
\hline Metallurgy $\ldots \ldots \ldots \ldots \ldots \ldots \ldots \ldots$ & -.003 \\
\hline Heavy industry $\ldots \ldots \ldots \ldots \ldots \ldots \ldots$ & $.029 * *$ \\
\hline Light industry $\ldots \ldots \ldots \ldots \ldots \ldots \ldots$ & $.045 * * *$ \\
\hline Wood and textile $\ldots \ldots \ldots \ldots \ldots \ldots . . . .$. & $.068 * * *$ \\
\hline Food industry $\ldots \ldots \ldots \ldots \ldots \ldots \ldots$ & $.031^{* *}$ \\
\hline Construction $\ldots \ldots \ldots \ldots \ldots \ldots \ldots \ldots$ & $.057 * * *$ \\
\hline Wholesale $\ldots \ldots \ldots \ldots \ldots \ldots \ldots \ldots$. & $.032 *$ \\
\hline Retail $\ldots \ldots \ldots \ldots \ldots \ldots \ldots \ldots \ldots \ldots$ & .019 \\
\hline Transport $\ldots \ldots \ldots \ldots \ldots \ldots \ldots \ldots$ & -.009 \\
\hline Services $\ldots \ldots \ldots \ldots \ldots \ldots \ldots \ldots \ldots$ & -.001 \\
\hline Constant $\ldots \ldots \ldots \ldots \ldots \ldots \ldots \ldots \ldots \ldots \ldots$ & $-1.613 * * *$ \\
\hline$N, \ldots \ldots \ldots \ldots \ldots \ldots \ldots \ldots \ldots \ldots \ldots \ldots \ldots \ldots$ & 467 \\
\hline Adjusted $R^{2} \ldots \ldots \ldots \ldots \ldots \ldots \ldots \ldots \ldots \ldots \ldots \ldots$ & .472 \\
\hline 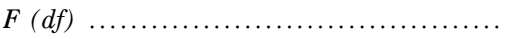 & $13.671(33)$ \\
\hline 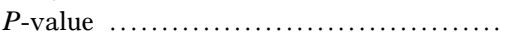 & .000 \\
\hline
\end{tabular}


American Journal of Sociology

etrating contact between business groups is destructive even beyond what we would expect to happen by chance-groups seem to break down more often if one or more of their members takes on multiple affiliations.

\section{RECOMBINANT LINEAGES OF COHESION}

Intercohesion represents a process of generative disruption. Business groups seem to face a fundamental contradiction: they appear forced to choose between striving either for stability or for high performance. On the one hand, choosing exclusivity can yield stability with attendant protection from failure but not with the possibility of high performance. Yet on the other, choosing intercohesive nonexclusivity opens up entrepreneurial possibilities and the promise of high performance, although at the risk of disintegration. This leaves groups with two possibilities: either they stay exclusive and stable, content with modest although secure performance, or they engage in intercohesive linking, possibly outperforming most other groups before they disintegrate.

However, our data indicate there is a third possibility that renders creative disruption manageable: groups connected by member exchange operate as larger collectivities, which absorb and hence limit the scattering of members from destabilized groups, thus mitigating the disruptions caused by structural folding. Instead of becoming dispersed across the whole range of groups in the entire economy, groups break up to rejoin with others near them and to regroup their resources in a fresh yet familiar combination. Instability thus becomes member recombination.

Our analyses thus far have worked with data that record changes from one point in time, $t$, to the next, $t+1$. In this section, we turn from a dynamic approach to a historical one by following the pattern of member flows across the entire epoch. In preceding sections, the unit of analysis was a group at a given point in time, and we estimated stability and effects on performance at the $t$ to $t+1$ interval. In this section, however, our unit of analysis is a collectivity of groups linked across time, and we follow the entire history of these collectivities through the historical structure of membership flows.

From nuclear groups, we now turn to broader kinship structures of business organization. The flows of members trace lineages among cohesive groups. Even though a group might not have shared any members with another in the past, it can still be connected to it through a chain of ancestry. Our intuition is that groups sharing an ancestry might stay close to one another, connected by intercohesive sharing of members and a common, repeatedly interwoven line of descent. A common ancestry makes group formation easier because routines of collaboration are al- 
ready familiar. This familiarity facilitates structural folding: groups that share an ancestry might be less likely to have radically different routines and cultures of collaboration, which would thus reduce the coordination costs attendant at the structural fold.

When are two groups related by a link of descent? According to Georg Simmel's idea of the persistence of identical selfhood in groups (Simmel 1898), a group of five members, $a, b, c, d, e$, is strongly related to a subsequent group with $m, b, c, d, e$ members. It is also clear that a group with $a, b, c, d, e$ is not related to a subsequent group of $f, g, h, i, j$. Between fully related and unrelated exist degrees of strength for a lineage tie. Being faithful to the founding impetus of social network analysis, we believe that the properties of a group are not a summary of the properties of its individual members. Instead, they emerge from the structure of interactions among members. This fundamental insight informs our definition of a lineage tie. It is doubtful that two groups can be related-in the sense that there is continuity in how the group operates and the purpose it serves-if they share only one member. Because group qualities stem from interaction along the ties that the group contains, it takes at least two members to establish continuity between their old group and their new group. Continuity in codes of communication and collaboration depends on some continuity in interaction. Therefore, continuity in trust and in routines of reciprocation and resource sharing cannot be transmitted by one member alone. In line with this insight, we define a lineage tie between a group at time $t$ and another group at time $t+1$ as the sharing of at least two members.

The idea of lineage ties extends the notion of the persistence of groups. Lineage ties link groups at adjacent points in time as ancestors or descendants. A lineage of cohesion represents a separate evolutionary path. Persistence concerns the length of the lineage: a group that persists over a long period, even if members are replaced along the way, is connected back in time to a long chain of groups. Persistence concerns only one dimension of a lineage-its length. Lineages can also have thicknessinvolving multiple groups at a given point in time, all connected by a shared ancestry. While some lineages are simple chains of linear persistence, other lineages are more complex, with branching and reunification. In this case, the structure of lineage ties is more complexly organized: members leaving a group will have a strong tendency to reform a group with others from the same lineage.

Figure 2 presents an example of an interwoven lineage. In 1995, this lineage starts with one group that has three structural folds with groups outside the lineage. In the following year, this group splits into two groups with overlapping memberships. Going forward, the two groups are not stable, but they do not dissolve entirely; the lineage is continued. 
American Journal of Sociology

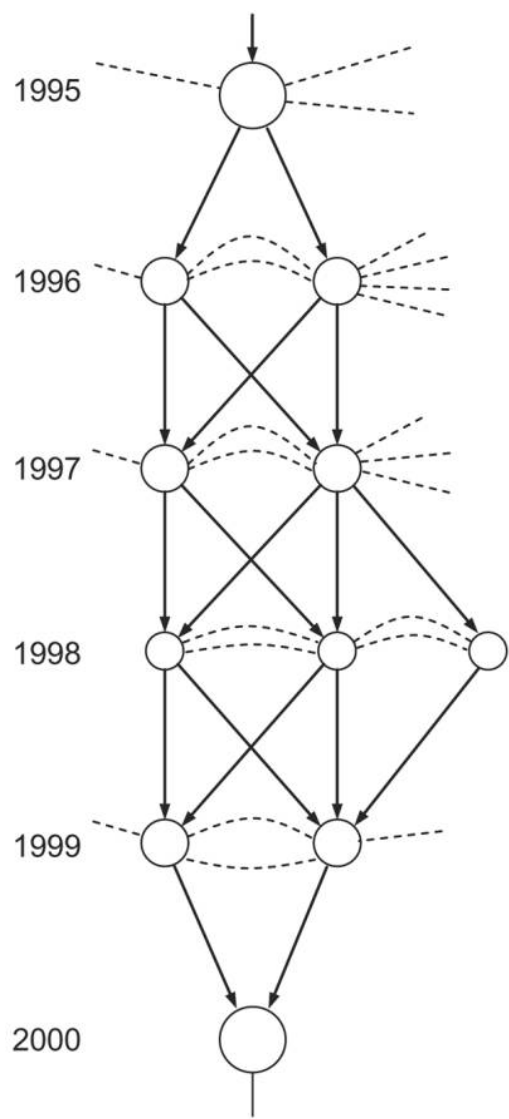

FIG. 2.-An example of an interwoven lineage. Circles represent groups, with size proportional to membership. Solid arrows represent member continuity of at least two firms; a dashed line indicates a structural fold.

The lineage presented in this example displays some distinctive structural properties. Later generations of groups-for example, the two groups in 1999-share an ancestry of cohesion that goes all the way back to 1995 (in the postsocialist context, an entire epoch). Beyond simply sharing the legacy of group routines from 1995, their lines of descent were repeatedly interwoven in such a way that they can, in fact, both trace a lineage to almost all of the preceding groups. This interwoven lineage contains groups that are linked by intercohesion at each point in time. These groups are not stable: almost all of them split up from one year to the next. Although the membership of individual groups is volatile, the membership of the lineage is stable. This is not to say that stability means stasis: at any point in time, groups within the lineage are recombined. 
We argue that the existence of interwoven lineages follows from an organizing principle that retains members of destabilized groups that are close to one another. But lineages - straight or interwoven-might also form when ties are created at random, that is, when a firm in a cohesive group has an equal probability of being a member of any of the groups in the coming year. To test clustering under such random conditions, we compare the observed size distribution of lineages with the size distribution in simulated data sets. If we find that lineages of similar size emerge often in random data, we can reject our hypothesis that lineages are a result of business organizing.

We ran simulations to test randomness as an explanation for the existence of lineages. In our simulations, we fix the degree distribution of incoming and outgoing lineage ties in each year, while randomizing the particular connections. In such a simulated data set, splitting occurs with the same probability in each year as it does in the observed data set in that given year, but members that split apart are randomly assigned to their target groups. The same holds for mergers-mergers happen with the same frequency as in the observed data set, but the particular mergers are randomly generated. Each simulation yields a complete lineage data set from 1987 to 2001. We generated 1,000 such data sets to estimate the distribution of lineage sizes when members migrate to other groups randomly.

Our findings indicate that it is very unlikely that the observed lineages are a result of randomly connected ties. As an illustration, figure 3 shows the 10 largest lineages in a representative simulated data set (where clustering statistics were closest to the mean of all simulations). Figure 4 shows the 10 largest lineages in the observed data set. The most striking difference between the simulated and the observed lineages is that the largest lineage in the simulated data is much larger than the second largest. Our first measure of lineage size distribution is the relative size of the largest lineage to the second largest. In our simulations, the largest lineage is, on average, 32 times the size of the second-largest lineage. In our observed data set, the largest lineage is about twice as large as the second. Only in eight of the one thousand simulations was this ratio smaller than or equal to two.

Another measure of clustering is the relative size of the largest lineage component to the size of the complete data set. In the observed data, the largest component encompassed only $14 \%$ of the total data set. In the one thousand simulated data sets, the largest component occupied, on average, $69 \%$ of a given data set. In only four of the one thousand simulations was the largest component as small as the largest component in the observed data set, namely $14 \%$. Lineages do not happen by accident.

We also found that interwoven lineages have dense intercohesive ties 

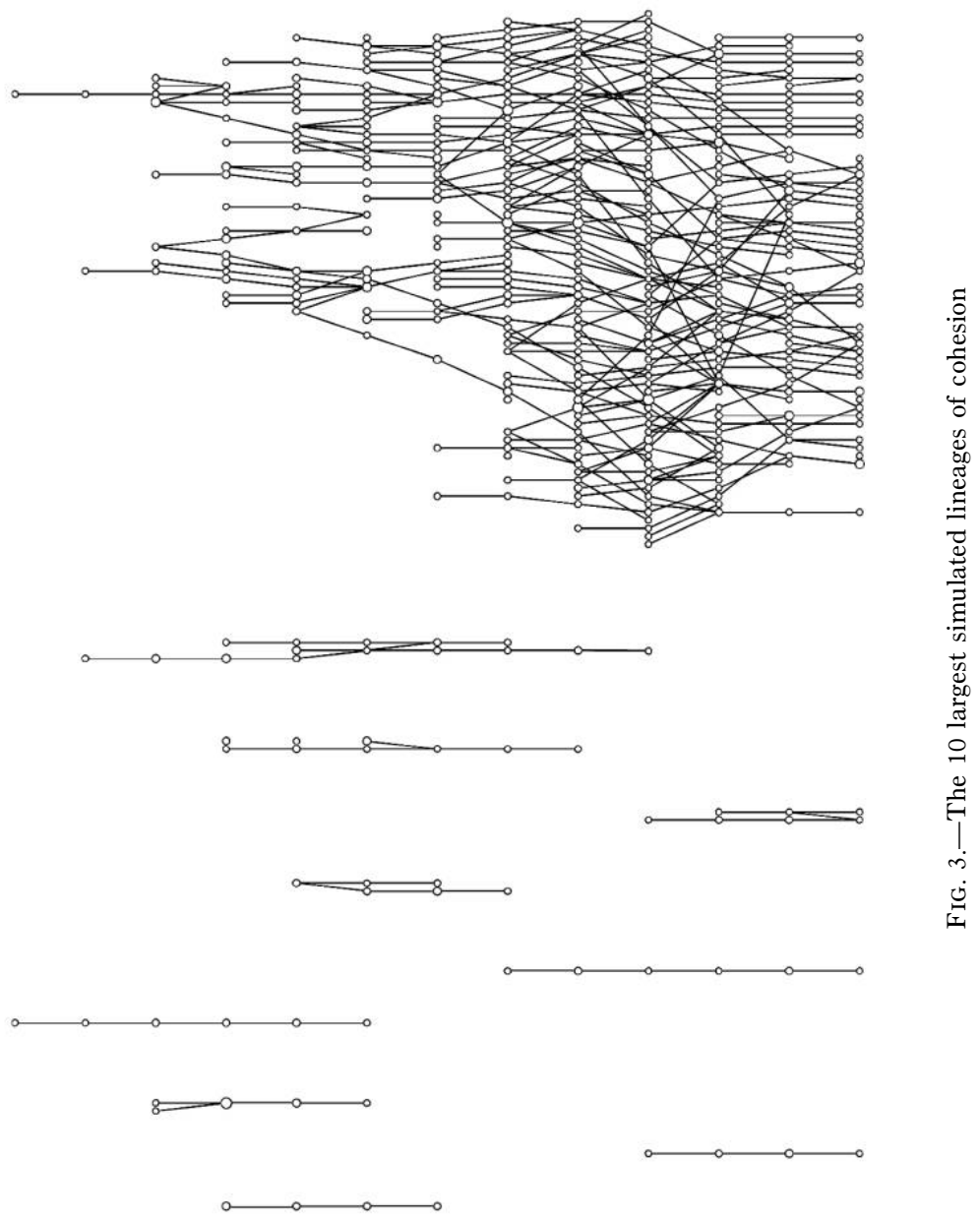

1180 


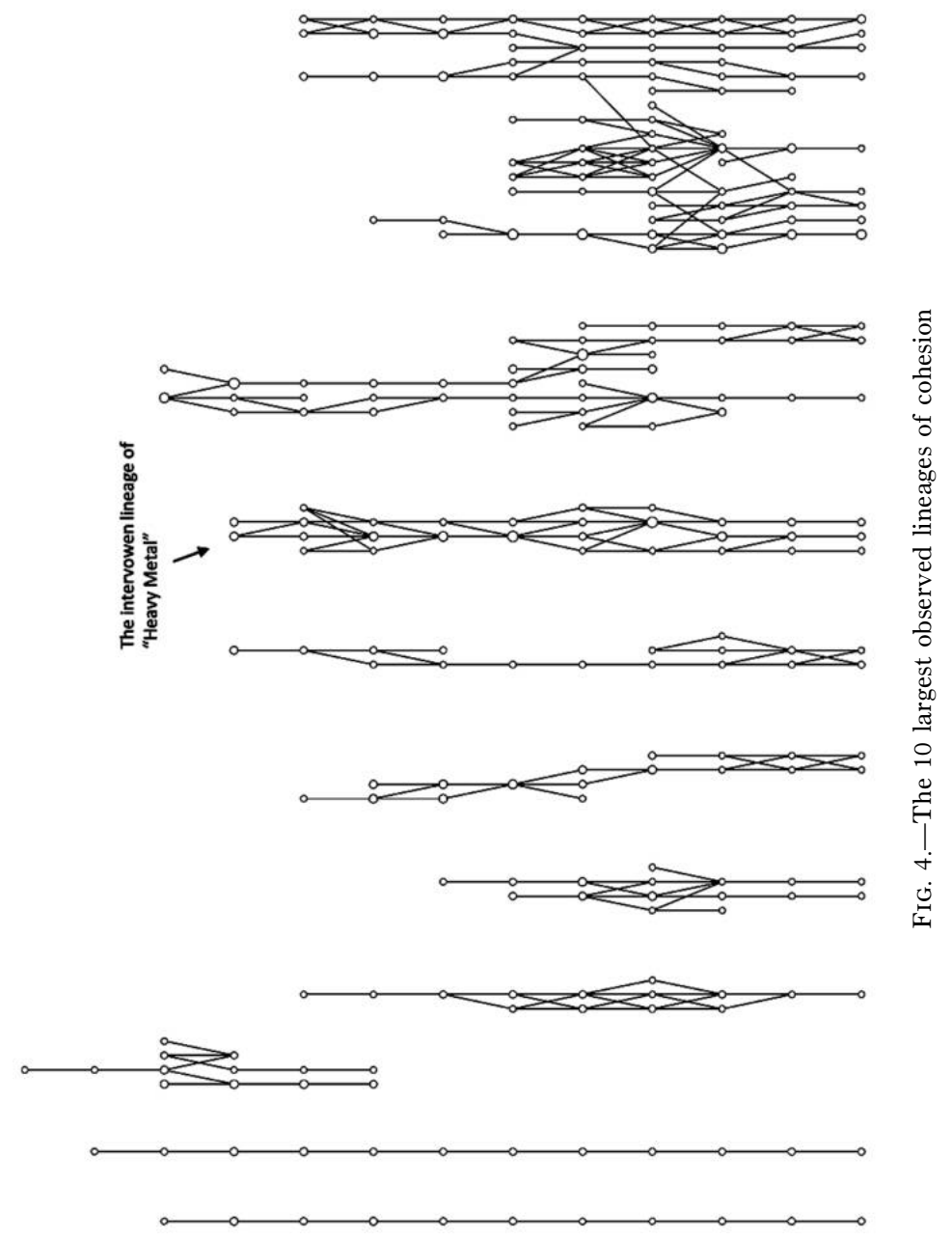

1181 
among the groups they contain. Looking at all the pairs of groups where intercohesion is possible (groups that coexisted in the same year), we found that the density of intercohesive ties is much higher for those pairs of groups that are within the same lineage. The density within interwoven lineages is $49 \%$, that is, almost half of the pairs of groups within such a lineage are connected by intercohesion. For example, in an interwoven lineage with four groups, three of the six possible pairs would be connected-enough to make the lineage a connected component. The density for pairs of groups that do not share a lineage is only $3 \%$. As a comparison, we computed the same density indices for the typical simulated lineage data set displayed in figure 3 . In this simulated data set, the intercohesion density within lineages is only $5 \%$-in contrast to $49 \%$ in the observed data.

In figure 4 we have also highlighted one of the interwoven lineages. This is the steel industry group "Heavy Metal," where Stark (1996) conducted ethnographic research during the early postsocialist period. This group is an interesting illustration of our social sequence method for identifying business groups across time. Heavy Metal is one of the relatively few business groups that exists as a named entity in the landscape of the Hungarian economy. In fact, the name of each firm indicates that it belongs to this business group. Of the 18 firms with the Heavy Metal designator in our data set, 17 of them are classified by our method in this interwoven lineage. The history of this business group, which started in 1992 and was studied by Stark in 1993-94, shows that organizational experimentation was not restricted to the early postsocialist period. Through repeated recombinations of subgroup memberships, the coherence of Heavy Metal is maintained amid changes in ownership and inflows of foreign direct investment, as well as across changes in government and shifting political affiliations.

In the context of business groups, a focus on lineages of cohesion highlights the fact that the organizing principle is more complex than merely bringing firms into close cohesive contact. The organization of business groups also involves strategic separation-keeping sets of members apart while, at the same time, maintaining historical coherence. The historical unfolding of organizing business groups leaves its traces as lineages of cohesion. Lineages highlight an important balancing between two forces. While the friction of intercohesion repeatedly dismantles groups, the shared lineage keeps members within a sphere of exchange in which member resources are redistributed and recombined. Intercohesion prevents groups from freezing into the defensive buffer of exclusivity, while lineage prevents groups from exploding and thus dissipating the resources they accumulated. 
Structural Folds

\section{CONCLUSION}

Social network analysis has produced a rich array of analytic concepts and powerful methods for studying structural features of economic action. From Granovetter's (1985) concept of embedded action, for example, sociology developed a systematic approach to predicting economic behavior from the structure of social ties. Methods of social network analysis designed to identify cliques, cores, clans, and other cohesive groups provided powerful operationalizations to the embeddedness concept. With White's concept of structural equivalence came the idea that actors might behave similarly not because they are linked together but because they share a common location within the more general pattern of ties. Using the method of block modeling, White and his colleagues turned scholarly attention away from the conventional understanding of networks as Who knows whom? to argue that absent ties were equally important (White, Boorman, and Breiger 1976). Along this line of thought, network analysis extended its attention to include patterns in the holes or missing spaces in social structure. Granovetter's (1973) idea of weak ties and Burt's (1992) concept of structural holes developed these insights into systematic analyses of brokerage opportunities, access to information, and structural constraint. Recently, Watts's concept of small worlds highlighted the joint importance of cohesive linking and long-distance ties reaching across structural voids for understanding flows of information (Watts 1999) and robustness in response to crisis (Dodds, Watts, and Sabel 2003).

Common to all these endeavors is the attention given to network topology. Each of the concepts-embedding, structural equivalence, weak ties, structural holes, small worlds-refers to specific topological network features. Our work contributes to these efforts by developing the concept of intercohesion and then identifying its corresponding topological feature where cohesive group structures fold into each other. While retaining the insight that structural properties are built from the presence and the absence of ties (the absence of ties across groups, exclusive of the structural fold, is significant in defining the groups as distinct units), we point to a distinctive position where cohesive network structures overlap and interpenetrate. Whereas Burt's conception of structural hole identifies a network location for brokerage, our conception of structural fold identifies a key network location in the entrepreneurial activity of recombination.

Thus, in contrast to Burt's image of a structure that bridges or spans a hole, we consider a site where structures fold together. Behind this difference of imagery lies a further difference in conceptualizing what is transpiring within networks. In the case of brokerage, social networks are channels, a means of transportation, a system of communication. Like electrical circuits, they conduct: the counterparts of electrons are, above 
all, pieces of information but also rumors and resources that flow through the network circuitry. According to this idea, network positions are important to the extent to which they are irreplaceable in maintaining flows between larger segments of the network.

If the flow or movement of information is the critical activity occurring through the conduit or at the contact point across the structural hole, it is the generation of knowledge through recombination that is the critical activity among intercohesive groups. Correspondingly, the electricity metaphor is replaced by more suitable ones from molecular chemistry. Instead of seeing networks as the wiring through which informational electrons flow, we should think of networks as a kind of molecular bonding in which ties connect nodes into larger groupings that represent a new molecular quality and not merely an extension of circuits to further atoms of the network. Intercohesion establishes strong connections between network molecules to generate a more complex material of creative alliances. In this view of a social network, flows are secondary. Information can be codified, but knowledge is a practice, bound up with particular sociotechnical ensembles. The more innovative the knowledge, the less likely it is to be fully codified and easily transmitted apart from these ensembles. Through the overlapping of strong ties bonding to more than one group, structural folding provides opportunities for mixing or recombining knowledge practices. Intercohesion is the process through which new ideas are generated, as opposed to a location where informational flows are taxed.

Whereas social network analysis has given us a plenitude of concepts for studying the structural properties of networks, the field has yielded far fewer concepts for analyzing the temporal or historical features of networks-despite the fact that Georg Simmel, one of the founding figures of network analysis, had addressed the temporal dimension in one of the first issues of the American Journal of Sociology. In his essay "Persistence of Social Groups," Simmel (1898) pondered whether it was meaningful to speak of group identity in cases of shifting membership and low institutionalization.

Simmel's challenge persists. More than a century later, social network analysis faces a fundamental theoretical and methodological problem when moving from a cross-sectional to a dynamic and historical concept of group cohesion. How can we identify a group across time in network terms? Can it change its composition and still preserve its group identity? The problem is simple where groups are named, cataloged, and registered, for example, the Supreme Court, the Youngstown Garden Club, the Mitsubishi keiretsu, or the Samsung Group. Despite membership changes over a century, the department of sociology at the University of Chicago remains such because of institutional continuity. But the social networks forming Hungarian corporate groups, like many of the groups studied by 
network analysts, lack such institutionalization. How do we study group evolution where groups might not be named?

Our work addresses this challenge directly. Drawing on Simmel's insights, we elaborate a conception of historical group identity based on membership continuity in contiguous stages. Such membership continuity need not be absolute, but there must be some overlap of (at least two) group members to bequeath groupness from one year to the next. The resulting operation yields another new way of representing network topology - a lineage of cohesion-in which structure can be displayed and analyzed across the temporal dimension. As we saw, some lineages take the form of a single, branchless line. But others-interwoven lineagesare built up through splitting and reuniting in an ongoing pattern of interweaving. In developing an historical network analysis, we combine attention to structure (characteristic of social network analysis) with attention to temporal processes (characteristic of historical sociology). The results make it possible to identify larger collectivities that would otherwise be invisible in static snapshots. This ability to recognize pattern in historical network data will have wide applicability for phenomena with low levels of institutionalization such as social movements, emerging industries, or new schools of scientific or literary thought.

Thus, as a direct counterpart to the topography of intercohesion along the synchronic dimension, we have identified interwoven lineages across the diachronic dimension. In a manner not dissimilar to structural folding - where we find recombination occurring at points of diversity within familiarity — we also find, along the historical dimension, that groups form and reform along lines of patterned coherence, separating to encompass greater diversity and rejoining to benefit from familiarity. Whether at the scale of intercohesion or along the historical dimension of interwoven lineages, the recombinant work of innovation requires the dual refrain of familiarity and diversity.

\section{APPENDIX}

The Clique Percolation Method

The clique percolation method operates on clique adjacency; $k$-cliques are adjacent if they share $k-1$ vertices. A clique of four is adjacent to another clique of four if they share three members. From adjacencies, one can assemble a clique chain, traversing along clique adjacencies. The union of all $k$-cliques in such a chain forms a $k$-clique percolation cluster if no more $k$-cliques can be added. This contiguous and highly cohesive region of the network is a cohesive group, within which a $k$-clique can percolate, or roll along, by always replacing only one of the $k$-nodes. Using a $k$ - 
value of four, as we do in this study, yields cohesive groups where all members have ties to at least three other members in the group.

Figure A1 illustrates the logic of the CPM method in identifying a small cohesive group. We start by identifying a 4-clique, and in step 1, this 4clique is rolled along by replacing one node. In step 2, the 4-clique is rolled further along, and in the final step, step 3, the group is identified, as there is no further possibility to roll the 4-click along.

The $k$-parameter of the CPM method is adjustable. The choice of a lower $k$ results in a more uneven distribution of group sizes. A $k$-value of one is of little use; if we consider the percolation of complete subgraphs of one node, this means that the whole network is one group. At this extreme value, the size distribution of groups is the most extreme-there is just one group that encompasses the whole network. A $k$ of two means that we consider the percolation of complete subgraphs of two nodes, which is equivalent to considering the percolation of edges. In this case, cohesive groups are the disconnected components of the graph. The size distribution of components is very skewed, because a giant component containing an overwhelming proportion of nodes is a common feature of networks. Increasing the value of $k$ to three means considering triangles (complete triads) as the percolating subgraph. Groups in this case are made of triangles sharing at least two nodes. The distribution of group sizes is more even, although in denser networks the largest triangle-percolation cluster can still be much larger than the second in size. Moving to a $k$ of four is even more restrictive, since groups need to be dense enough to allow the percolation of complete subgraphs of four. In this case, the distribution of group sizes is more even, and there might not be a group that is clearly the largest.

We decided to use a $k$-value of four in identifying clique percolation clusters. Most applications of the CPM method found that there is a percolation transition between a $k$-value of four and three. While a $k$ of four produces groups that are roughly of equal size, a $k$ of three produces a highly skewed group-size distribution (Palla et al. 2005). Our data confirm this finding: with a $k$ of three, the largest group is, on average, three times larger than the second-largest group, while in some years it is 5 times larger. With a $k$ of four, the largest group is, on average, 1.21 times larger than the second largest, and the maximal size distance is 1.57 (see table A1). Thus, we decide to use $k=4$ to identify cohesive groups with the CPM method. 


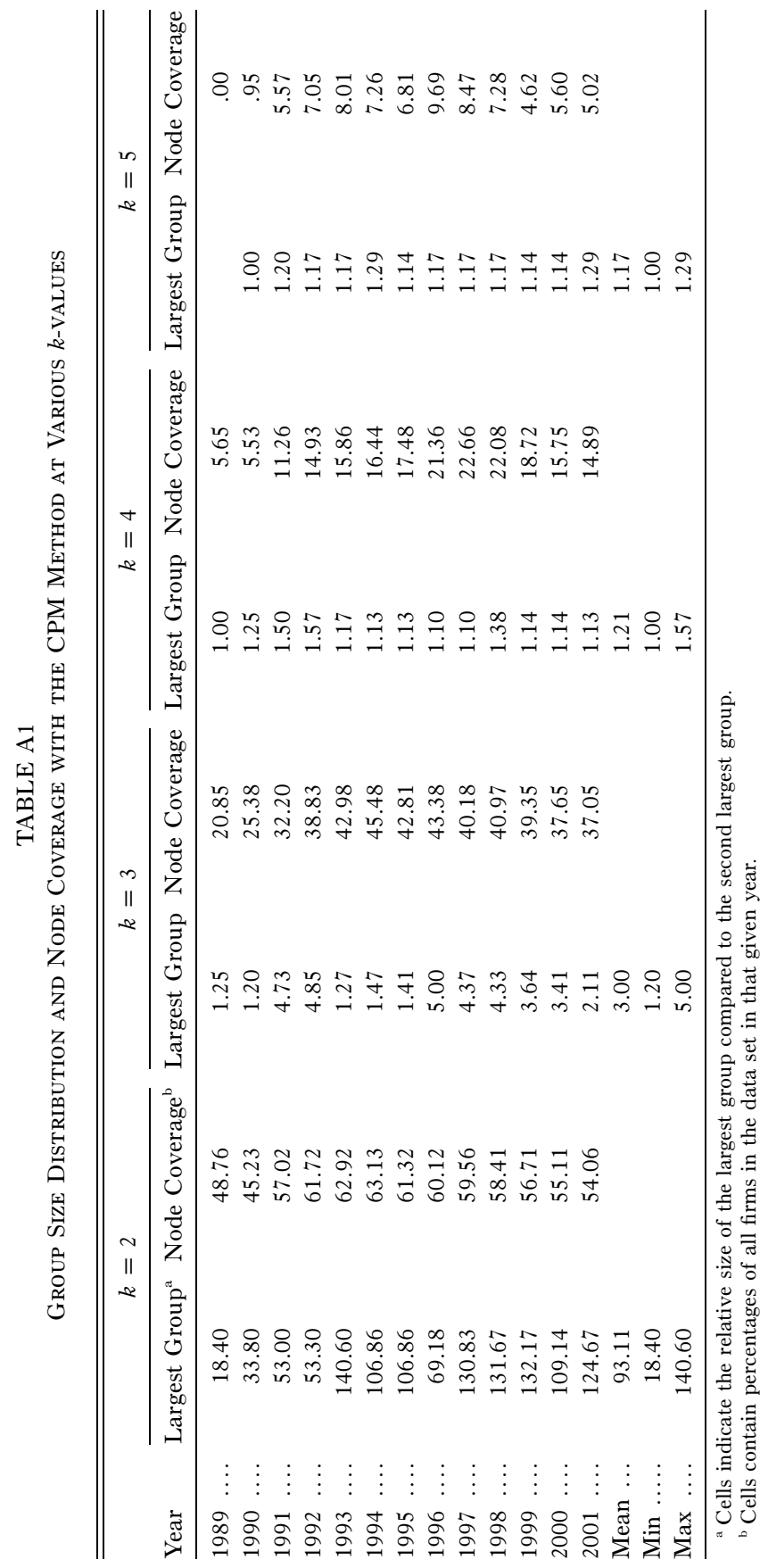




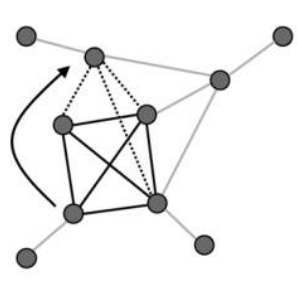

Step 1

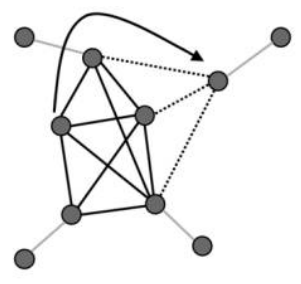

Step 2

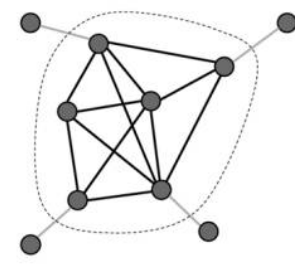

Step 3

FIG. A1.-Illustrating the logic of the CPM algorithm

\section{REFERENCES}

Baum, Joel A. C., Bill McEvily, and Tim Rowley. 2007. "Better with Age: The Longevity and the Performance Implications of Bridging and Closure." Working paper no. 1032282. Rotman School of Management, University of Toronto.

$\rightarrow$ Breiger, Ronald L. 1974. "The Duality of Persons and Groups." Social Forces 53 (2): 181-90.

$\rightarrow$ Brudner, Lilyan A., and Douglas R. White. 1997. "Class, Property, and Structural Endogamy: Visualizing Networked Histories.” Theory and Society 26:161-208.

$\rightarrow$ Burris, Val. 2005. "Interlocking Directorates and Political Cohesion among Corporate Elites." American Journal of Sociology 111 (1): 249-83.

Burt, Ronald S. 1992. Structural Holes: The Social Structure of Competition. Cambridge, Mass.: Harvard University Press.

. 2005. Brokerage and Closure. Oxford: Oxford University Press.

$\rightarrow$ - 2008. "Information and Structural Holes: Comment on Reagans and Zuckerman." Industrial and Corporate Change 17 (5): 953-69.

Dewey, John. (1938) 1998. “The Pattern of Inquiry.” Pp. 169-79 in The Essential Dewey, vol. 2, Ethics, Logic, Psychology. Edited by Larry A. Hickman and Thomas M. Alexander. Bloomington, Ind.: Indiana University Press.

$\rightarrow$ Dodds, Peter Sheridan, Duncan J. Watts, and Charles F. Sabel. 2003. "Information Exchange and the Robustness of Organizational Networks." Proceedings of the National Academy of Sciences 100 (21): 12516-21.

Everett, Martin G., and Stephen P. Borgatti. 1998. "Analyzing Clique Overlap." Connections 21 (1): 49-61.

$\rightarrow$ Fernandez-Mateo, Isabel. 2007. "Who Pays the Price of Brokerage? Transferring Constraint through Price Setting in the Staffing Sector." American Sociological Review 72 (2): 291-317.

Festinger, Leon, Stanley Schachter, and Kurt W. Back. 1950. Social Pressures in Informal Groups: A Study of Human Factors in Housing. New York: Harper.

$\rightarrow$ Field, Sam, Kenneth A. Frank, Kathryn Schiller, Catherine Riegle-Crumb, and Chandra Muller. 2006. "Identifying Positions from Affiliation Networks: Preserving the Duality of People and Events." Social Networks 28:97-123.

Figyelő. 2002. "Kétszázak klubja 2001." In Figyelő Top 200.

$\rightarrow$ Freeman, Linton C. 1992. "The Sociological Concept of 'Group': An Empirical Test of Two Models." American Journal of Sociology 98 (1): 152-66.

$\rightarrow$ Friedkin, Noah E. 2004. "Social Cohesion." Annual Review of Sociology 30:409-25.

Gould, Roger V. 2003. Collision of Wills: How Ambiguity about Social Rank Breeds Conflict. Chicago: University of Chicago Press. 
$\rightarrow$ Granovetter, Mark. 1973. "The Strength of Weak Ties." American Journal of Sociology 78 (6): $1360-80$.

$\rightarrow-1985$. "Economic Action and Social Structure: The Problem of Embeddedness." American Journal of Sociology 91 (3): 481-510.

. 2005. "Business Groups and Social Organization." Pp. 429-50 in Handbook of Economic Sociology, 2d ed. Edited by Neil Smelser and Richard Swedberg. Princeton, N.J.: Princeton University Press; New York: Russell Sage.

$\rightarrow$ Khanna, Tarun, and Jan W. Rivkin. 2001. "Estimating the Performance Effects of Business Groups in Emerging Markets." Strategic Management Journal 22:45-74.

$\rightarrow$ Kogut, Bruce, and Udo Zander. 1992. "Knowledge of the Firm, Combinative Capabilities, and the Replication of Technology." Organization Science 3:383-97.

Lester, Richard K., and Michael J. Piore. 2004. Innovation: The Missing Dimension. Cambridge, Mass.: Harvard University Press.

$\rightarrow$ Lincoln, James R., Michael L. Gerlach, and Christina L. Ahmadjian. 1996. "Keiretsu Networks and Corporate Performance in Japan." American Sociological Review 61: $67-88$.

$\rightarrow$ McPherson, Miller, and Lynn Smith-Lovin. 2002. "Cohesion and Membership Duration: Linking Groups, Relations and Individuals in an Ecology of Affiliation." Advances in Group Processes 19:1-36.

$\rightarrow$ McPherson, Miller, Lynn Smith-Lovin, and James M. Cook. 2001. "Birds of a Feather: Homophily in Social Networks." Annual Review of Sociology 27:415-44.

$\rightarrow$ Mizruchi, Mark S. 1996. "What Do Interlocks Do? An Analysis, Critique, and Assessment of Research on Interlocking Directorates." Annual Review of Sociology 22: 271-98.

$\rightarrow$ Mizruchi, Mark S., and Linda Brewster Stearns. 1988. "A Longitudinal Study of the Formation of Interlocking Directorates." Administrative Science Quarterly 33: 194-210.

$\rightarrow$ Moody, James A., and Douglas R. White. 2003. "Structural Cohesion and Embeddedness: A Hierarchical Concept of Social Groups." American Sociological Review 68 (1): $103-27$.

Moreno Jacob L. and Helen H. Jennings. 1937. "Statistics of Social Configurations." Sociometry 1 (3/4): 342-74.

Nyírő, András, and István Szakadát. 1993. Politika Interaktív. CD-ROM. Budapest: Aula.

$\rightarrow$ Obstfeld, David. 2005. "Social Networks, the Tertius Iungens Orientation, and Involvement in Innovation." Administrative Science Quarterly 50 (1): 100-30.

$\rightarrow$ Padgett, John F., and Paul D. McLean. 2006. "Organizational Invention and Elite Transformation: The Birth of Partnership Systems in Renaissance Florence." American Journal of Sociology 111 (5): 1463-1568.

$\rightarrow$ Palla, Gergely, Imre Derényi, Illés Farkas, and Tamás Vicsek. 2005. "Uncovering the Overlapping Community Structure of Complex Networks in Nature and Society." Nature 435 (7043): 814-18.

$\rightarrow$ Palla, Gergely, Albert László Barabási, and Tamás Vicsek. 2007. "Quantifying Social Group Evolution.” Nature 466 (7136): 664-67.

$\rightarrow$ Powell, Walter W., Douglas R. White, Kenneth W. Koput, and Jason Owen-Smith. 2005. "Network Dynamics and Field Evolution: The Growth of Interorganizational Collaboration in the Life Sciences." American Journal of Sociology 110 (4): $1132-1205$.

Schumpeter, Joseph A. 1934. The Theory of Economic Development. Cambridge, Mass.: Harvard University Press.

- 2003. Essays: On Entrepreneurs, Innovations, Business Cycles, and the Evolution of Capitalism. New Brunswick, N.J.: Transaction.

$\rightarrow$ Sewell, William H., Jr. 1992. "A Theory of Structure: Duality, Agency and Transformation." American Journal of Sociology 98:1-29. 
American Journal of Sociology

$\rightarrow$ Simmel, Georg. 1898. "The Persistence of Social Groups." American Journal of Sociology 3 (5): 662-98.

. (1922) 1964. Conflict and the Web of Group Affiliations. New York: Free Press.

$\rightarrow$ Skvoretz, John, and Katherine Faust. 1999. "Logit Models for Affiliation Networks." Sociological Methodology 29:253-80.

$\rightarrow$ Spicer, Andrew, Gerald A. McDermott, and Bruce Kogut. 2000. "Entrepreneurship and Privatization in Central Europe: The Tenuous Balance between Destruction and Creation." Academy of Management Review 25:630-49.

$\rightarrow$ Stark, David. 1996. "Recombinant Property in East European Capitalism." American Journal of Sociology 101 (4): 993-1027.

2009. The Sense of Dissonance: Accounts of Worth in Economic Life. Princeton, N.J.: Princeton University Press.

Stark, David, and Laszlo Bruszt. 1998. Postsocialist Pathways: Transforming Politics and Property in East Central Europe. New York: Cambridge University Press.

$\rightarrow$ Stark, David, and Balázs Vedres. 2006. "Social Times of Network Spaces: Network Sequences and Foreign Investment in Hungary." American Journal of Sociology 111 (5): $1367-1412$.

$\rightarrow$ Thye, Shane R., Jeongkoo Yoon, and Edward J. Lawler. 2002. "The Theory of Relational Cohesion: Review of a Research Program." Advances in Group Processes 19:139-66.

$\rightarrow$ Useem, Michael. 1980. "Corporations and the Corporate Elite." Annual Review of Sociology 6:41-77.

$\rightarrow$ Uzzi, Brian. 1997. "Social Structure and Competition in Interfirm Networks: The Paradox of Embeddedness." Administrative Science Quarterly 42:35-67.

$\rightarrow$ Uzzi, Brian, and Jarrett Spiro. 2005. "Collaboration and Creativity: The Small World Problem." American Journal of Sociology 111 (2): 447-504.

Wasserman, Stanley, and Katherine Faust. 1994. Social Network Analysis: Methods and Applications. New York: Cambridge University Press.

$\rightarrow$ Watts, Duncan J. 1999. "Networks, Dynamics and the Small-World Phenomenon." American Journal of Sociology 105:493-527.

$\rightarrow$ - 2004. "The 'New' Science of Networks." Annual Review of Sociology 30: 243-70.

$\rightarrow$ Weitzman, Martin L. 1998. "Recombinant Growth." Quarterly Journal of Economics 113 (2): 331-60.

White, Douglas R., and Ulla C. Johansen. 2005. Network Analysis and Ethnographic Problems: Process Models of a Turkish Nomad Clan. Lanham, Md.: Lexington Books.

$\rightarrow$ White, Harrison C., Scott A. Boorman, and Ronald L. Breiger. 1976. "Social Structure from Multiple Networks, I: Blockmodels of Roles and Positions." American Journal of Sociology 81 (4): 730-80.

$\rightarrow$ Wuchty, Stefan, Ben Jones, and Brian Uzzi. 2007. "The Increasing Dominance of Teams in the Production of Knowledge." Science 316:1036-39. 